\title{
Sphingosine kinase 2 activates autophagy and protects neurons against ischemic injury through interaction with Bcl-2 via its putative BH3 domain
}

\author{
Dan-Dan Song ${ }^{1,4}$, Tong-Tong Zhang ${ }^{1,4}$, Jia-Li Chen ${ }^{1}$, Yun-Fei Xia ${ }^{1}$, Zheng-Hong Qin ${ }^{1}$, Christian Waeber ${ }^{2,3}$ and Rui Sheng ${ }^{\star, 1}$
}

Our previous findings suggest that sphingosine kinase 2 (SPK2) mediates ischemic tolerance and autophagy in cerebral preconditioning. The aim of this study was to determine by which mechanism SPK2 activates autophagy in neural cells. In both primary murine cortical neurons and HT22 hippocampal neuronal cells, overexpression of SPK2 increased LC3Il and enhanced the autophagy flux. SPK2 overexpression protected cortical neurons against oxygen glucose deprivation (OGD) injury, as evidenced by improvement of neuronal morphology, increased cell viability and reduced lactate dehydrogenase release. The inhibition of autophagy effectively suppressed the neuroprotective effect of SPK2. SPK2 overexpression reduced the co-immunoprecipitation of Beclin-1 and Bcl-2, while Beclin-1 knockdown inhibited SPK2-induced autophagy. Both co-immunoprecipitation and GST pulldown analysis suggest that SPK2 directly interacts with Bcl-2. SPK2 might interact to Bcl-2 in the cytoplasm. Notably, an SPK2 mutant with L219A substitution in its putative BH3 domain was not able to activate autophagy. A Tat peptide fused to an 18-amino acid peptide encompassing the native, but not the L219A mutated BH3 domain of SPK2 activated autophagy in neural cells. The Tat-SPK2 peptide also protected neurons against OGD injury through autophagy activation. These results suggest that SPK2 interacts with Bcl-2 via its BH3 domain, thereby dissociating it from Beclin-1 and activating autophagy. The observation that Tat-SPK2 peptide designed from the BH3 domain of SPK2 activates autophagy and protects neural cells against OGD injury suggest that this structure may provide the basis for a novel class of therapeutic agents against ischemic stroke.

Cell Death and Disease (2017) 8, e2912; doi:10.1038/cddis.2017.289; published online 6 July 2017

Sphingolipids, the major components in eukaryotic lipid bilayers and prokaryotic cell membranes, play important roles in cell survival and death. ${ }^{1}$ Sphingosine 1-phosphate (S1P) promotes cell survival and proliferation, while ceramide and sphingosine inhibit cell growth and induce cell apoptosis. ${ }^{2}$ Both isoforms of sphingosine kinases (SPK1 and SPK2) catalyze the phosphorylation of sphingosine to S1P, thereby controlling, together with S1P-degrading enzymes, the balance of sphingolipid species. SPK2 is likely to play a role in various diseases, such as cancer, ${ }^{3,4}$ cardiovascular diseases $^{5,6}$ and inflammation. ${ }^{7-10}$ Recent studies also demonstrate that SPK2 is involved in stroke, preconditioning and neuronal autophagy ${ }^{11-13}$ and may be a potential therapeutic target for the prevention and management of cerebral ischemia. But the mechanistic link between SPK2 and preconditioning or neuroprotection remains to be defined.

Autophagy is a dynamic process in eukaryotic cells that removes proteins or damaged organelles for recycling. In neurons, the autophagosomes at different maturation states in the cell soma are derived from distinct neuronal compartments, possibly to facilitate autophagosome degradation by fusion with lysosomes enriched in the soma. Surprisingly, neither rapamycin, a traditional autophagy inducer, nor nutrient deprivation induced neuronal autophagy as that in non-neuronal cells. This may indicate that the primary role of constitutive autophagy in neurons is to effectively turnover aging proteins and organelles to maintain homeostasis, rather than to mobilize amino acids under starvation. ${ }^{14}$ Autophagy may contribute to the neuroprotection induced by ischemic, hypoxic and isoflurane preconditioning (ISO). ${ }^{15-17}$ Various sphingolipids, including ceramide and S1P, have been shown to be involved in the regulation of autophagy. ${ }^{18} \mathrm{~S} 1 \mathrm{P}$ produced by SPK1 overexpression in cell lines activates autophagy, possibly via suppression of mTOR activity and mild accumulation of Beclin-1. ${ }^{19,20}$ Cytoplasmic S1P generated by SPK1 enhances autophagy flux in neurons, ${ }^{21}$ whereas the S1P lyase, a kind of S1P-metabolizing enzyme, downregulates autophagy. ${ }^{22}$ However, the contribution of SPK2 to autophagy within neurons remains to be elucidated. Our previous findings showed that the endogenous SPK2 isoform contributes to autophagy activation induced by ISO and hypoxic preconditioning. ${ }^{17}$ Interestingly, the SPK2 mediated autophagy and protection seemed to be S1P-independent, but possibly due to the disruption of Beclin-1/Bcl-2 interaction. ${ }^{17}$ SPK2 contains a 9-amino acid sequence similar to that seen in pro-apoptotic BH3-only proteins; indeed, SPK2 induces apoptosis in different cell types. ${ }^{23} \mathrm{BH} 3$-only proteins such as Bad and BNIP3 have been shown to mediate autophagy by disrupting the interaction between Beclin-1 and Bcl-2 or $\mathrm{BCl}-\mathrm{X}_{\mathrm{L}}{ }^{24-26}$ We previously hypothesized that SPK2 might

\footnotetext{
${ }^{1}$ Department of Pharmacology and Laboratory of Aging and Nervous Diseases, Soochow University School of Pharmaceutical Science, Suzhou, China; ${ }^{2}$ Department of Pharmacology and Therapeutics, University College Cork, Cork, Ireland and ${ }^{3}$ School of Pharmacy, University College Cork, Cork, Ireland

*Corresponding author: R Sheng, Department of Pharmacology and Laboratory of Aging and Nervous Diseases, Soochow University School of Pharmaceutical Science, 199 Ren Ai Road, Suzhou 215123, China. Tel/Fax: +86 512 65882071; E-mail: sheng_rui@163.com

${ }^{4}$ These authors contributed equally to this work.

Received 13.2.17; revised 26.5.17; accepted 29.5.17; Edited by GM Fimia
} 
similarly induce autophagy by interaction with $\mathrm{Bcl}-2$ via its $\mathrm{BH}$ domain. ${ }^{17}$

In the present study, we directly examined the effect of overexpressed SPK2 in primary cultured murine cortical neurons and HT22 neuronal cells to test the hypothesis that SPK2 could protect neural cells from ischemic injury by activating autophagy. Next we explored the mechanisms underlying autophagy activation induced by SPK2.

\section{Results}

SPK2 protects neurons from oxygen and glucose deprivation injury. Neuronal and/or microvascular SPK2 have been shown to play a role in cerebral preconditioning. ${ }^{11-13}$ To examine whether SPK2 can directly protect against ischemic injury, we overexpressed SPK2 in primary murine cortical neurons; lentivirus-mediated SPK2 overexpression in cortical neurons was monitored with GFP immunofluorescence (Figure 1a). SPK2 and HA-Tag protein overexpression was confirmed by western blot analysis (Figures $1 \mathrm{~b}$ and $\mathrm{c}$ ). We also established a stable SPK2overexpressing cell line (LV-SPK2-HT22 cells) by infecting HT22 cells with SPK2 lentivirus. SPK2, but not SPK1, was upregulated in LV-SPK2-HT22 cells (Supplementary Figure S1a), and the SPK2 activity significantly increased compared with LV-vector-HT22 cells (Supplementary Figure S1b). Cortical neuron cultures were then oxygen and glucose deprived for $4 \mathrm{~h}$ (OGD). Cell viability and cytotoxicity were determined using Cell Counting Kit-8 (CCK8) and lactate dehydrogenase (LDH) assay kits, respectively. OGD significantly decreased the viability and membrane integrity of cortical neurons, whereas SPK2-overexpressing neurons showed reduced cell death, as evidence by increased cell viability (Figure 1d), reduced LDH leakage (Figure 1e) and improved neuronal morphology (Figure 1f) compared with neurons infected with LV-vector.

Overexpression of SPK2 induces autophagy activation. To expand on our previous observation that SPK2 may protect neurons through autophagy activation, ${ }^{17}$ we examined autophagic activity in SPK2-overexpressing neurons. The LC3II was increased after SPK2 overexpression compared with LV-vector-infected neurons. OGD upregulated LC3II, in agreement with published results, ${ }^{16,27-31}$ while SPK2 overexpression further increased LC3II after OGD treatment (Figure 2a). We then examined the autophagic flux in SPK2overexpressing neurons using ammonium chloride $\left(\mathrm{NH}_{4} \mathrm{Cl}\right)$, an inhibitor of lysosome-phagosome fusion. ${ }^{32,33}$ The LC3II/ actin ratio in the presence versus absence of $\mathrm{NH}_{4} \mathrm{Cl}$ increased in SPK2-overexpressing neurons compared with vectorinfected neurons (Figure 2b), suggesting that overexpression of SPK2 enhanced autophagic flux. Similar to the results in cortical neurons, the LC3II in LV-SPK2-HT22 was much higher than that in LV-vector-HT22 cells (Supplementary Figure S2a), and SPK2 overexpression enhanced autophagy flux in LV-SPK2-HT22 cells as well (Supplementary Figure S2b). 3-Methyladenine (3-MA) is a specific autophagy inhibitor that blocks the formation of autophagosomes. ${ }^{34}$ Pretreatment with 3-MA at a concentration known to block autophagy
$(10 \mathrm{mM})^{16,35,36}$ abolished the neuroprotection induced by SPK2 overexpression, as evidenced by reduced cell viability (Figure 2c) and increased LDH leakage (Figure 2d). All these results suggest that SPK2 mediates autophagy activation and contributes to the ischemic tolerance.

Overexpression of SPK2 interferes with the interaction of Beclin-1 and Bcl-2. Beclin-1, the mammalian homolog of yeast Apg6/Nps30, is a key regulator of autophagy. ${ }^{37}$ To test the hypothesis that the autophagy activation by SPK2 involves the Beclin-1 pathway, we examined the effect of siRNAmediated Beclin-1 knockdown on autophagic activity. In SPK2overexpressing neurons, Beclin-1 was effectively downregulated by two different Beclin-1 siRNAs (Figure 3a). Treatment with Beclin-1 siRNAs also markedly inhibited SPK2-induced LC3II upregulation (Figure 3b), suggesting that SPK2 activates autophagy in a Beclin-1-dependent manner. Beclin-1 interacts with $\mathrm{Bcl}-2$ via its $\mathrm{BH} 3$ domain, ${ }^{25,38}$ this interaction prevents Beclin-1 from activating autophagy, and autophagy is initiated when Beclin-1 is released from the Beclin-1/Bcl-2 complex. $^{39,40}$ To confirm our previous hypothesis that SPK2 can interfere with the interaction between Beclin-1 and Bcl-2, ${ }^{17}$ we further examined the co-immunoprecipitation of Beclin-1 and Bcl-2 in cortical neuron lysates. Beclin-1/Bcl-2 coimmunoprecipitation was reduced when SPK2 was overexpressed in cortical neurons (Figure 3c), confirming that SPK2 might disrupt the interaction between Beclin-1 and Bcl2 , resulting in autophagy activation.

SPK2 interacts with Bcl-2. We then set out to test the hypothesis that SPK2 induces autophagy by interacting with $\mathrm{Bcl}-2$ and examined the interaction of SPK2 and Bcl-2 by co-immunoprecipitation and GST pull-down analysis in lysates of SPK2-overexpressing HT22 cells. Bcl-2 was coimmunoprecipitated when HA-SPK2 was immunoprecipitated using $\mathrm{HA}$ antibodies, whereas $\mathrm{Bcl}-2$ barely precipitated in cell lysates in the absence of HA-SPK2 (Figure 4a). Correspondingly, HA-SPK2 was co-immunoprecipitated when Bcl-2 was precipitated (Figure $4 \mathrm{~b}$ ). The interaction of SPK2 with $\mathrm{Bcl}-2$ was further assessed by in vitro pull-down experiments using GST-Bcl-2 or GST alone bound to glutathione-agarose and lysates of SPK2- or vector-infected HT22 cells. The data demonstrated a specific interaction of SPK2 with GST-Bcl-2 but not with GST alone (Figure 4c). These results, taken together with the fact that SPK2 dissociates the complex between Beclin-1 and Bcl-2, further confirm that SPK2 interacts with $\mathrm{Bcl}-2$ to release Beclin-1 from Beclin-1/Bcl-2 complex and to activate autophagy.

In neurons, SPK2 could be expressed in the cytoplasm, mitochondria and nucleus under physiological or pathological conditions. ${ }^{41-44}$ Our previous finding showed that preconditioning mainly upregulates endogenous SPK2 in the cytoplasm. On the other hand, apoptosis-stimulating protein of p53-2 (ASPP2) could bind to Bcl-2 in the nucleus to prevent its translocation to the cytoplasm, thus contributing to Beclin-1initiated autophagy. ${ }^{45}$ We then examined the cellular distribution of SPK2 and whether Bcl-2 translocates to the nucleus when SPK2 is overexpressed in neural cells. The immunofluorescence (Figure 5a) and western blot analysis (Figure 5b) showed that SPK2 was overexpressed in both the cytoplasm 
a

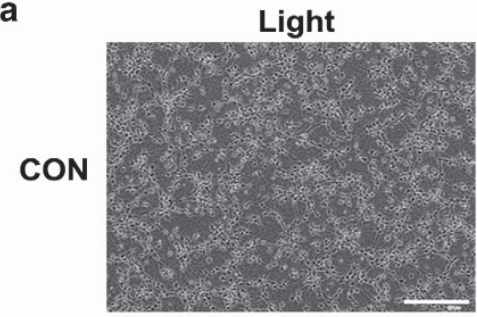

SPK2

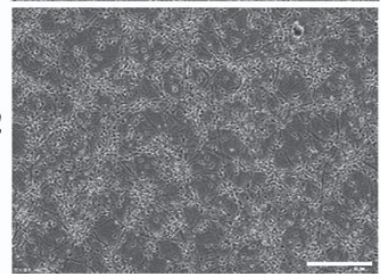

b

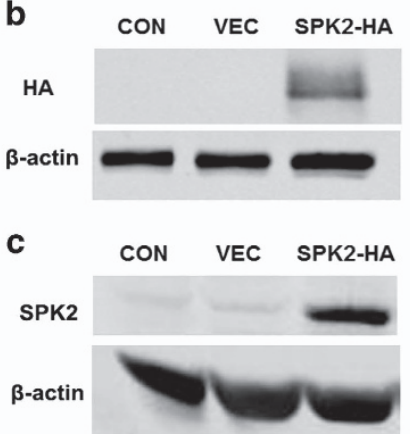

d

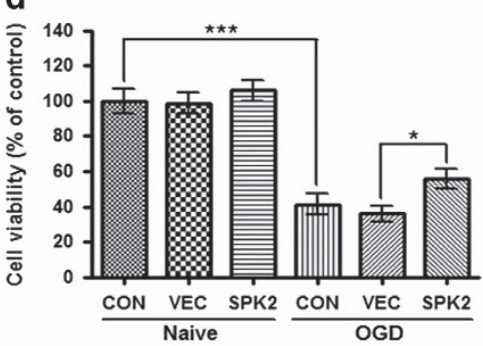

f

\section{CON}

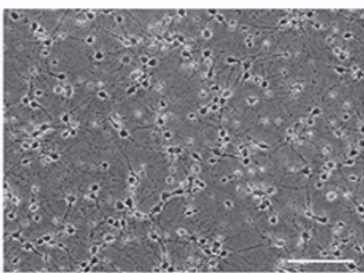

NAIVE

GD

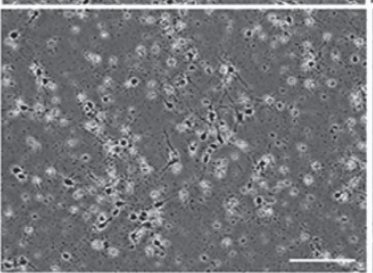

42KD

69KD

42KD

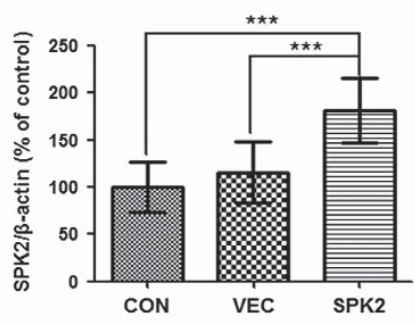

e

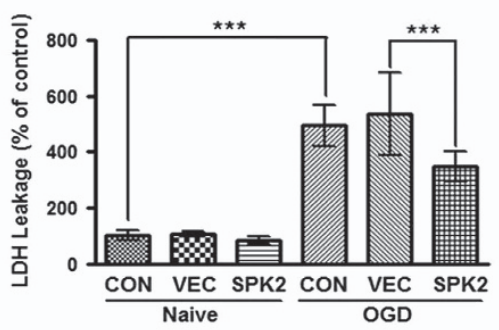

CON VEC

SPK2
VEC

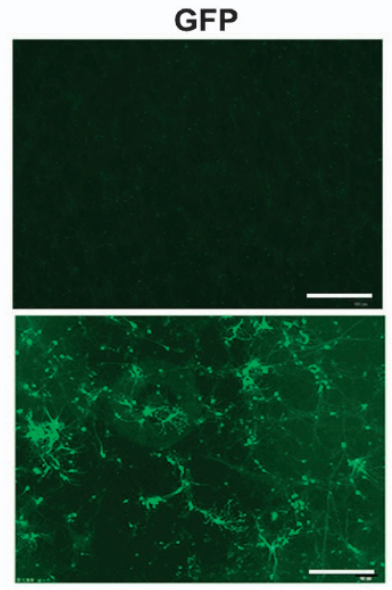

SPK2

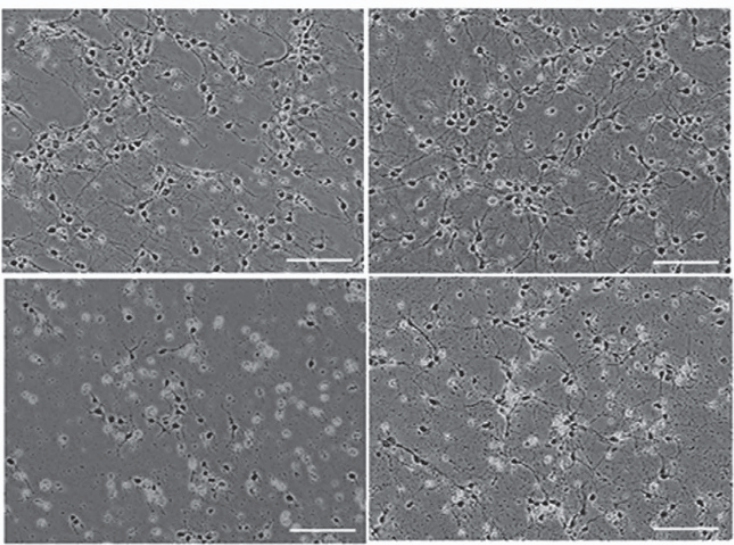

Figure 1 SPK2 overexpression protected primary cortical neurons from OGD injury. (a) Cortical neurons were infected with LV-SPK2 or LV-vector at DIV2. At DIV 7, the neurons were visualized with bright field, and the efficiency of infection was detected by GFP fluorescence. Scale bar $=100 \mu \mathrm{m}$. (b and $\mathbf{c})$ Overexpression of SPK2 was induced by lentivirus gene infection. Neurons were harvested and subjected to western blot analysis against HA-tag (b) or SPK2 (c). (d) SPK2 protected cortical neurons from OGD injury. Cortical neurons were exposed to OGD for $4 \mathrm{~h}$. The cell viability was examined with Cell Counting Kit-8 assay. (e) Cytotoxicity was examined with LDH assay after OGD treatment for $4 \mathrm{~h}$. (f) The neuronal morphology was observed by optical microscope. Scale bar $=100 \mu \mathrm{m}$. Bar represents mean \pm S.D., $n=3$ independent experiments. ${ }^{*} P<0.05$, ${ }^{* * *} P<0.001$ 

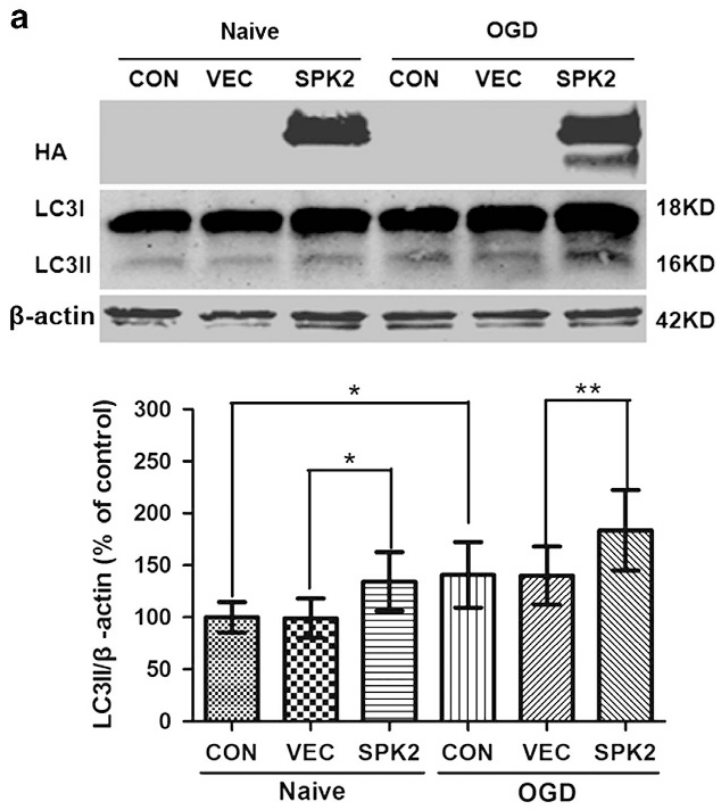

C

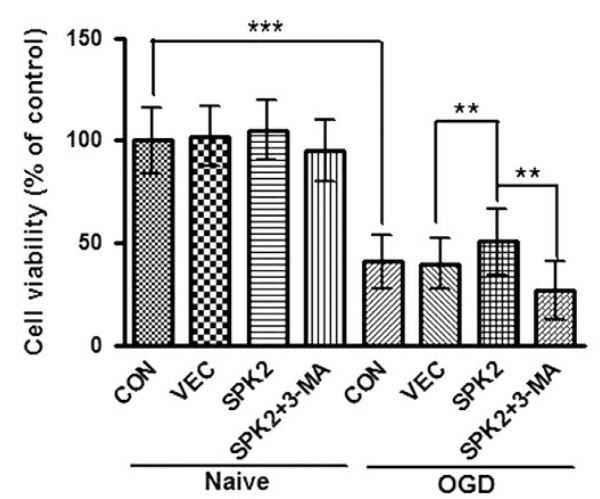

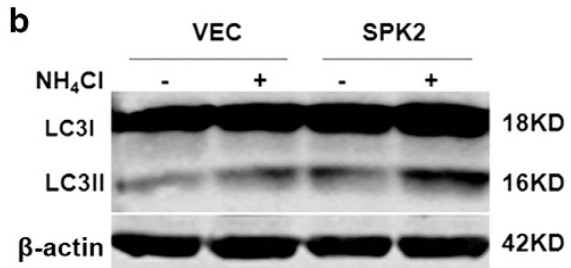
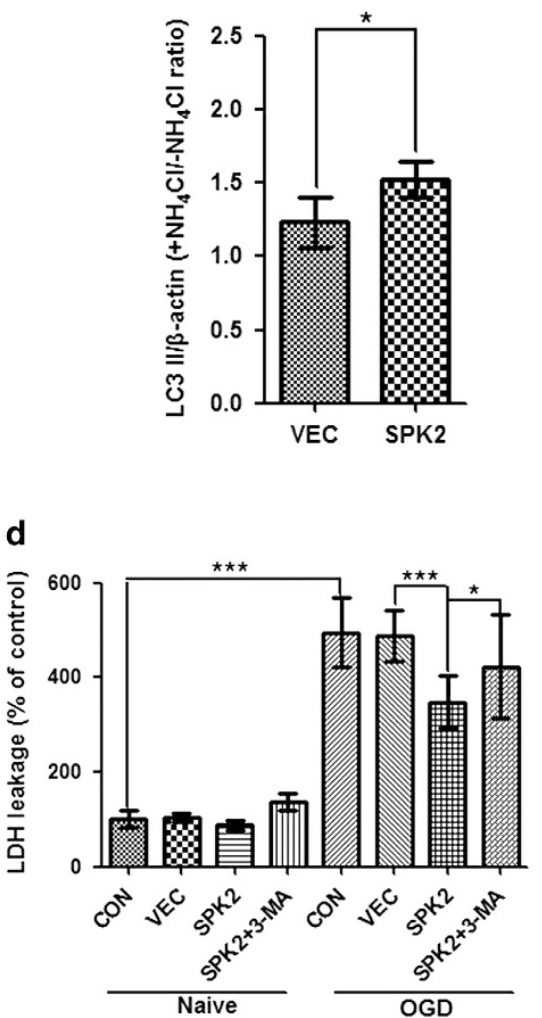

Figure 2 SPK2 overexpression induced autophagy activation in cortical neurons. (a) LC3II was upregulated in LV-SPK2-transfected neurons. Neurons were exposed to OGD for $4 \mathrm{~h}$. After OGD treatment, cortical neurons transfected with LV-vector or LV-SPK2 were harvested and subjected to western blot analysis. (b) Autophagic flux was examined by comparing LC3II/actin with or without $\mathrm{NH}_{4} \mathrm{Cl}$. Neurons were treated with $\mathrm{NH}_{4} \mathrm{Cl}$ ( $20 \mathrm{mM}$ ) for $24 \mathrm{~h}$. (c and d) 3-MA abolished the neuroprotection induced by SPK2 overexpression. The neurons were treated with 3-MA $(10 \mathrm{mM})$ for $24 \mathrm{~h}$ during OGD reperfusion. Cell counting kit-8 (c) and LDH release (d) was examined to determine cell viability and cytotoxicity. Bar represents mean \pm S.D., $n=3$ independent experiments. ${ }^{*} P<0.05,{ }^{* \star} P<0.01,{ }^{* \star *} P<0.001$

and nucleus of LV-SPK2-HT22 cells. In SPK2-overexpressing neurons, however, although SPK2 was also overexpressed in both cytoplasm and nucleus, its cytoplasmic content is much higher than that in nuclear fraction (Figure $5 \mathrm{c}$ ). Bcl-2 was mainly expressed in the cytoplasm of both LV-SPK2-HT22 cells and SPK2-overexpressing neurons. There was no significant nuclear translocation of $\mathrm{Bcl}-2$ under SPK2 overexpression. We also examined the cellular distribution of endogenous SPK2 in neurons after ISO, a noxious stimulus that could be applied conveniently to elicit neuroprotection in vivo and in vitro. ${ }^{11}$ The results showed that SPK2 was expressed in both cytoplasm and nucleus of control neurons. After ISO treatment, SPK2 was upregulated in the cytoplasm instead of nucleus (Figure $5 d$ ), consistent with our previous data of immunofluorescence assay showing that ISO increased the endogenous SPK2 mainly in a cytoplasmic manner. ${ }^{17}$ Importantly, ISO greatly increased the colocalization of endogenous SPK2 and Bcl-2 in cytoplasm (Figure 5e).
All these results suggest that SPK2 might interact to Bcl-2 in the cytoplasm of neurons.

Mutation in the putative BH3 domain of SPK2 (SPK2-L219A) prevents autophagy activation. SPK2 contains a 9-amino acid motif found in the sequence of pro-apoptotic BH3-only proteins, and a $\mathrm{Leu}^{219}$ to Ala substitution in this sequence was previously shown to decrease the pro-apoptotic effect of overexpressed mutant SPK2 (Figure 6a). ${ }^{23}$ Because some $\mathrm{BH} 3$-only proteins (e.g., Bad and BNIP3) mediate autophagy by disrupting the interaction between Beclin-1 and $\mathrm{Bcl}-2$ or $\mathrm{Bcl}-\mathrm{X}_{\mathrm{L}},{ }^{25,26}$ we then tested the hypothesis that the effect of SPK2 on autophagy is dependent on its $\mathrm{BH} 3$ domain. To do so, we mutated Leu ${ }^{219}$ to Ala and use the mutant SPK2 lentivirus to establish a stable LV-L219A-HT22 cell line. The apoptosis in the SPK2 overexpressed HT22 cells was examined by Hoechst staining. The basal apoptotic rate of LV-vector- 
a

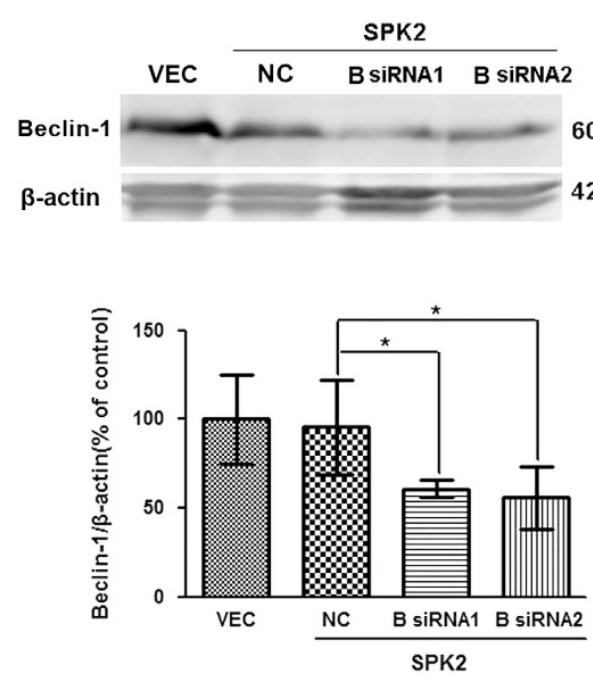

b

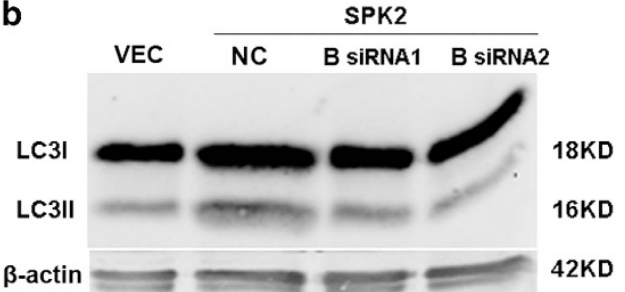

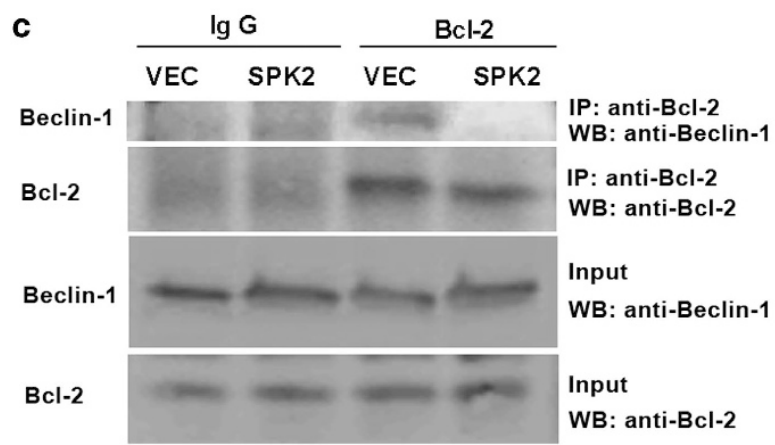

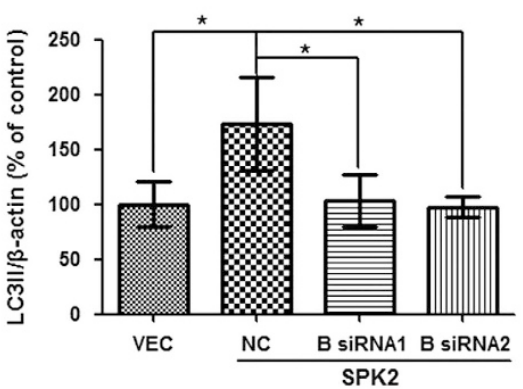

Figure 3 SPK2 disrupted Beclin-1/Bcl-2 complex to activate autophagy in cortical neurons. (a and $\mathbf{b}$ ) Beclin-1 knockdown abolished SPK2-induced autophagy activation. Cortical neurons transfected with LV-vector or LV-SPK2 were further transfected with Beclin-1 siRNA on DIV6. Beclin-1 (a) and LC3 levels (b) were measured by western blotting (c) SPK2 disrupted Beclin-1/Bcl-2 complex. Lysates were immunoprecipitated with anti-Bcl-2, separated by SDS-PAGE and subjected to blot analysis with the indicated antibody. Bar represents mean \pm S.D., $n=3$ independent experiments. ${ }^{*} P<0.05$. NC, negative control

HT22 cells is about $1.3 \%$, and there is no significant difference in apoptotic rate among LV-SPK2-HT22, LV-L219A-HT22 and LV-vector-HT22 cells, suggesting that SPK2 overexpression did not induce significant apoptosis in neural cells (Supplementary Figure S3). Western blot quantification showed similar SPK1 levels in all cell lines (Figure 6b), but immunoreactivity for HA-Tag and for SPK2 were significantly higher in both LV-SPK2-HT22 and LV-L219A-HT22, compared with LV-vector-HT22 and control cells (Figure 6b). Furthermore, the LC3II was elevated in LV-SPK2-HT22 cells, but not in LV-L219A-HT22 cells (Figure 6c). Transmission electron microscope (TEM) was used to survey the extent of autophagosome formation in LVSPK2-HT22 and LV-L219A-HT22 cells. HT22 cells infected with LV-vector appeared normal with relatively healthylooking organelles and nuclei. The organelles and nuclei in LV-SPK2-HT22 and LV-L219A-HT22 cells also seemed normal without appreciable injury, but more double-membrane or multi-membrane vacuolar structures were found in the LV-SPK2-HT22 cells than that in LV-vector-HT22 and LV-L219A-HT22 cells (Figure 6d), providing morphological evidence that the putative $\mathrm{BH} 3$ domain of SPK2, and more specifically Leu ${ }^{219}$, plays an important role in SPK2-induced autophagy activation.

Tat-SPK2 peptide induces autophagy activation. We hypothesized that the $\mathrm{BH} 3$ domain of SPK2 might be sufficient to induce autophagy, and designed cell permeable Tat-SPK2 and Tat-L219A peptides composed of an 18-amino acid segment encompassing the $\mathrm{BH} 3$ domain of wild type or L219A-mutant SPK2, N-terminally conjugated to biotin ${ }^{46,47}$ (Figure 6a). By imaging cells stained with Alexa Fluor 488streptavidin conjugate, we confirmed that biotin-conjugated Tat-SPK2 was able to penetrate HT22 cell membranes (Figure 7a). Treatment with $10 \mu \mathrm{M}$ Tat-SPK2 peptide, but not Tat-L219A, increased the LC3II after 1h, indicating that Tat-SPK2 peptide did activate autophagy (Figure 7b). The LC3II in the presence versus absence of lysosomal protease inhibitor $\mathrm{NH}_{4} \mathrm{Cl}$ increased after Tat-SPK2 treatment at 1 and $3 \mathrm{~h}$ (Figure 7c), suggesting that autophagic flux was maintained up to $3 \mathrm{~h}$ after peptide treatment. The results of TEM showed that more double-membrane or multi-membrane vacuolar structures were found in HT22 cells treated with $10 \mu \mathrm{M}$ Tat-SPK2 peptide for $1 \mathrm{~h}$ than in the control group 
a

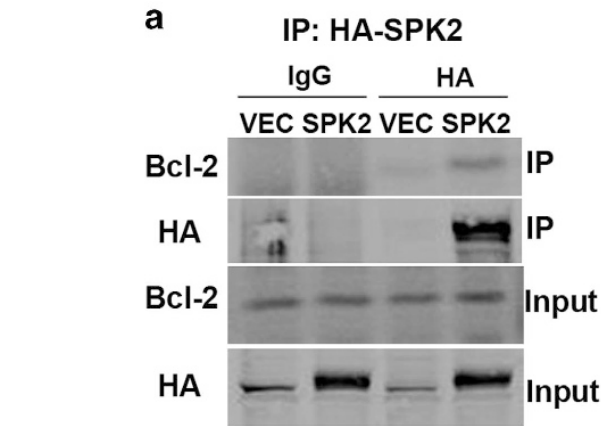

b

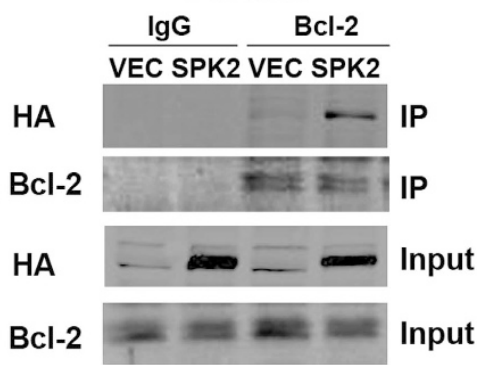

C

GST GST-BCl-2 VEC SPK2 VEC SPK2

HA

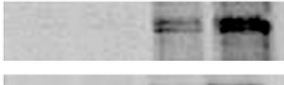

pull down

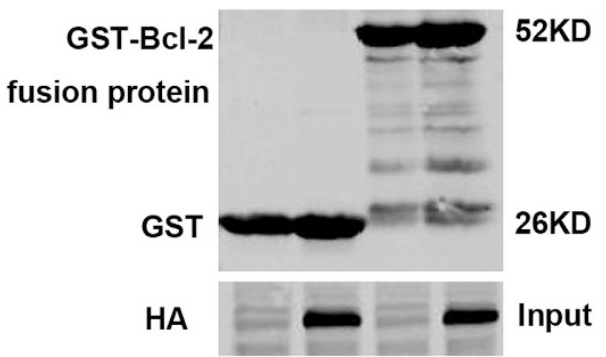

Figure 4 SPK2 interacts with Bcl-2 in HT22 cells. (a) Stable transfected LV-SPK2-HT22 cell lysates were immune-precipitated with anti-HA, separated by SDS-PAGE, and subjected to western blot analysis with anti-Bcl-2. (b) Cell lysates were immunoprecipitated with anti-Bcl-2, separated by SDS-PAGE, and subjected to western blot analysis with anti-HA. (c) GST-Bcl-2 or GST bound to glutathione-agarose, incubated with lysates of LV-HA-SPK2-transfected HT22 cells and subjected to western blot analysis with anti-HA. $n=3$ independent experiments

instead of Tat-L219A peptide (Figure 7d). All these results suggested that Tat-SPK2 peptide could activate autophagy.

Tat-SPK2 peptide protects HT22 cells and primary neurons from OGD injury. We then investigated whether Tat-SPK2 peptide treatment induced ischemic tolerance in HT22 cells and primary neurons. In HT22 cells, $10 \mu \mathrm{M}$ Tat-SPK2 peptide but not Tat-L219A significantly enhanced cell viability compared with OGD alone (Figure 8a). Notably, pretreatment with autophagy inhibitor 3-MA effectively abolished Tat-SPK2-induced protection (Figure 8b). Atg5 is a crucial gene involved in autophagosome biogenesis. ${ }^{48,49}$ Two siRNAs directed against Atg5 were used to inhibit the induction of autophagy. Atg5 protein was efficiently reduced by Atg5 siRNAs compared with the negative control (NC). Knockdown of Atg5 could effectively abolish the neuroprotection induced by Tat-SPK2, further suggesting autophagy is involved in Tat-SPK2-mediated ischemic tolerance (Figure 8c). In primary neurons, Tat-SPK2 peptide at concentrations of 0.01 to $0.1 \mu \mathrm{M}$ also increased the cell viability compared with OGD alone or Tat-L219A group (Figure 8d). All these results suggested that Tat-SPK2 peptide could protect neural cells against OGD injury by autophagy activation.

\section{Discussion}

The goal of the study was to expand on previous findings showing that SPK2 mediates ischemic tolerance and autophagy in cerebral preconditioning, ${ }^{17}$ and to explore the mechanism underlying autophagy activation induced by SPK2. There are many measurements to monitor autophagy, such as monitoring LC3II conversion, autophagy flux, autophagosomes or autolysomes, and detection of Atg proteins or other signals in the autophagy pathway, etc. ${ }^{50}$ In this study, we examined the LC3 levels, determined autophagy flux by using a lysosome inhibitor and used transmission election microscopy to observe autophagosomes and autolysosomes. In both primary murine cortical neurons and HT22 neuronal cells, SPK2 overexpression was associated with upregulated LC3II and enhanced autophagy flux. Knockdown of Beclin-1 inhibited SPK2-induced autophagy. SPK2 overexpression exerted neuroprotection against OGD injury in cortical neurons, and these effects were suppressed by autophagy inhibitor 3-MA. Our results indicated that SPK2 can interact with $\mathrm{Bcl}-2$ via its $\mathrm{BH} 3$ domain, leading to the dissociation of Bcl-2 from Beclin-1 complex and to autophagy activation (Figure 9). Furthermore, the results of our experiments with Tat-SPK2 peptide suggested that agents mimicking the $\mathrm{BH} 3$ domain of SPK2 might be used therapeutically to induce autophagy and/or neuroprotection.

SPK2 can be upregulated by various preconditioning stimuli to mediate neuroprotection against cerebral ischemia ${ }^{11-13}$ and SPK2-mediated ischemic tolerance seems to involve autophagy. ${ }^{17}$ Data in this report confirmed previous findings and established causality by showing that SPK2 overexpression led to upregulated LC3II and enhanced autophagy flux, protected cortical neurons from OGD injury, whereas 3-MA, an 
a

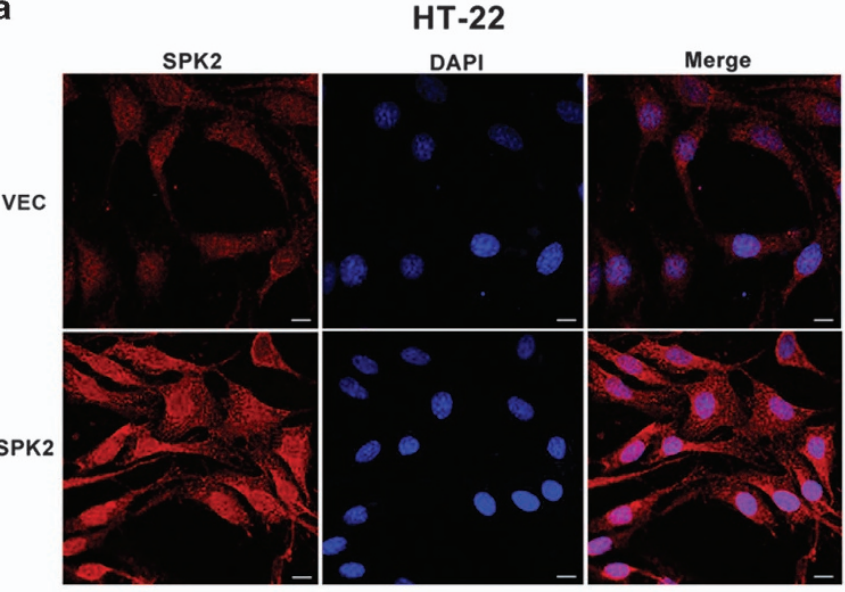

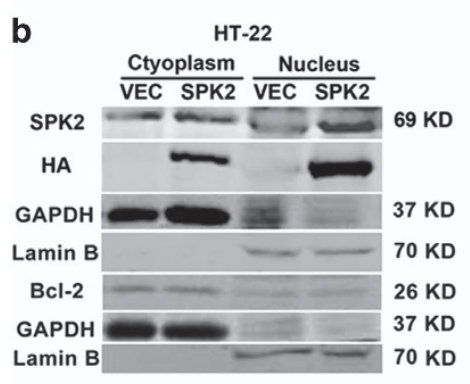

C

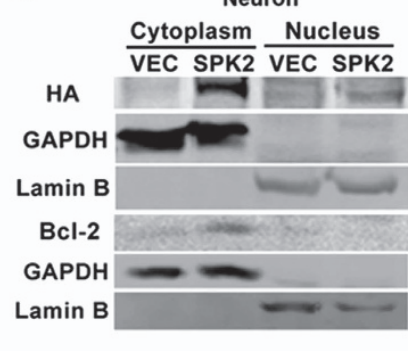

d

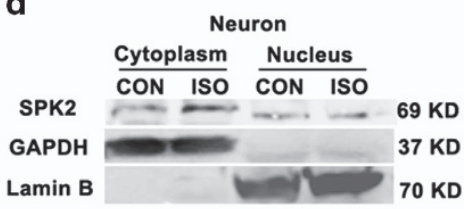

e

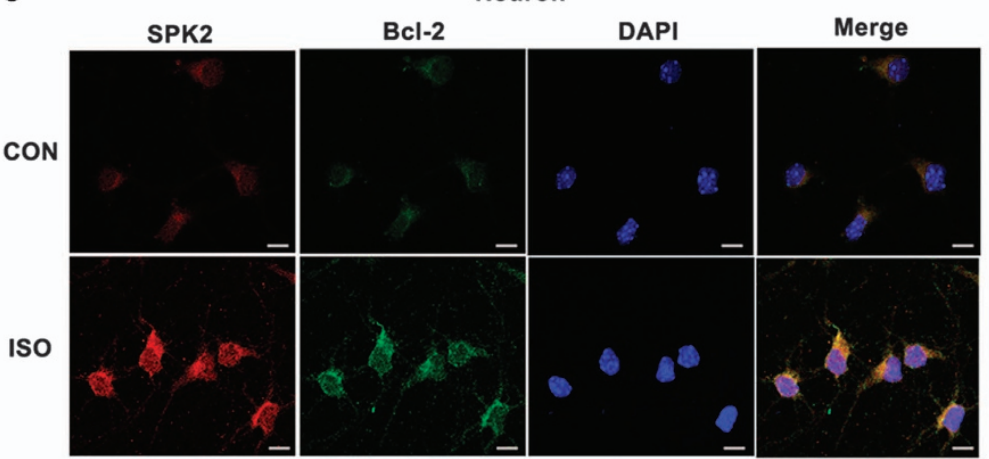

Figure 5 The distribution of SPK2 in the cytoplasm and nuclear fraction of neural cells. (a) LV-vector-HT22 and LV-SPK2-HT22 cells were fixed with 4\% paraformaldehyde and processed for immunofluorescence. Representative images were stained with DAPI (blue) and antibody against SPK2 (red). Scale bar $=10 \mu \mathrm{m}$. (b) Nuclei and cytoplasm of LV-vector-HT22 and LV-SPK2-HT22 cells were extracted and subjected to western blot analysis. (c) Cortical neurons were infected with LV-SPK2 or LV-vector at DIV2. At DIV 7 , the nuclei and cytoplasm of neurons were extracted and subjected to western blot analysis. (d) The distribution of SPK2 in the cytoplasm and nuclear fraction of neurons after isoflurane preconditioning (ISO). The neurons were exposed to $2 \%$ ISO for $30 \mathrm{~min}$. Twenty-four hours later, the cytoplasmic and nuclear fractions of neurons were extracted and subjected to western blot analysis. (e) ISO increased the colocalization of SPK2 and Bcl-2 in the cytoplasm of neurons. Neurons were fixed with $4 \%$ paraformaldehyde and processed for immunofluorescence. Representative images were stained with DAPI (blue), and antibodies against SPK2 (red) and Bcl-2 (green). Scare bar $=10 \mu \mathrm{m}$. $n=3$ independent experiments

autophagy inhibitor, effectively suppressed SPK2 elicited neuroprotection against OGD. All these results indicated that SPK2-induced autophagy activation contributes to its neuroprotection against OGD injury.

We previously hypothesized that SPK2-mediated autophagy during preconditioning was due to disruption of the interaction between Beclin-1 and Bcl-2, rather than to SPK2 catalytic activity. ${ }^{17}$ We now tested whether SPK2 overexpression directly activates autophagy via the Beclin-1 pathway. Our results showed that knockdown of Beclin-1 effectively suppressed the autophagy activation by SPK2, and
SPK2 reduced the amount of co-immunoprecipitation of Beclin-1 and Bcl-2. In addition, both co-immunoprecipitation and GST pull-down analysis demonstrated that SPK2 directly interacted with $\mathrm{Bcl}-2$. These results strongly suggested that SPK2 disrupts Beclin-1/Bcl-2 complexes via its interaction with $\mathrm{Bcl}-2$ to release free Beclin-1 and to activate autophagy.

Based on sequence analysis, SPK2 contains a 9-amino acid motif similar to the sequence in $\mathrm{BH} 3$-only proteins ${ }^{51}$ which contribute to cell apoptosis in some cancer cell lines. ${ }^{23}$ Beclin-1, via its $\mathrm{BH} 3$ domain, also interacts with $\mathrm{Bcl}-2$ or 

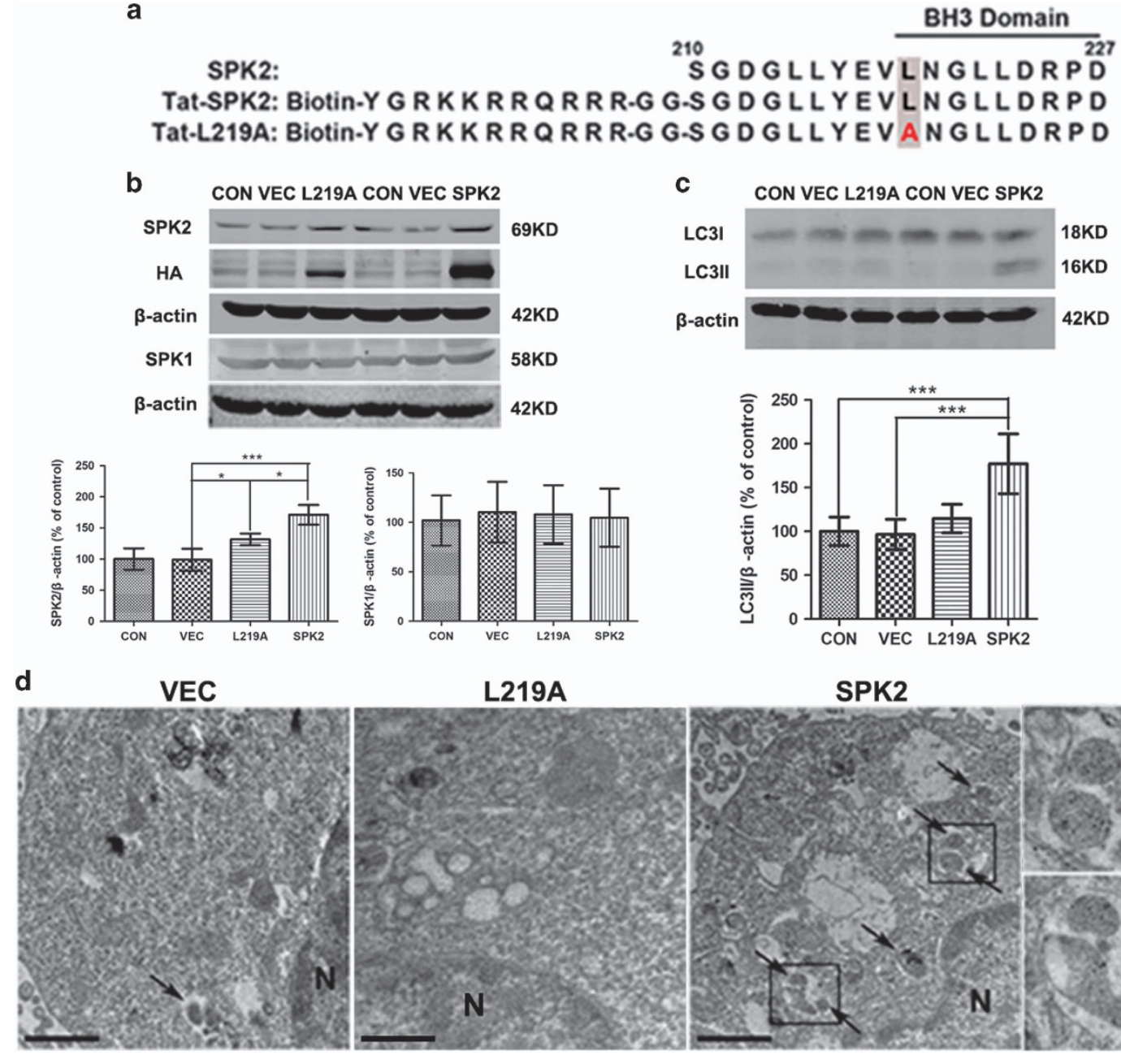

Figure 6 SPK2-L219A mutation prevents autophagy activation in HT22 cells. (a) Sequences of SPK2 amino acids 210-227, Tat-SPK2 and Tat-L219A peptide. (b) SPK2 and SPK1 expression in LV-L219A-HT22 and LV-SPK2-HT22 cells. The control, LV-vector, LV-SPK2 and LV-L219A-HT22 cells were harvested and subjected to western blot analysis. (c) LC3II was not upregulated in LV-L219A-HT22 as LV-SPK2-HT22 cells. (d) Electron microscopic images show increased number of double-membrane vacuolar structure in the LV-SPK2-HT22 but not in LV-L219A-HT22 cells. Scale bar $=1 \mu \mathrm{m}$. Arrows point to autophagosomes or autolysosomes. N: nucleus. Insets show the enlarged autophagosomes or autolysosomes taken from the boxed areas. Bar represents mean \pm S.D., $n=3$ independent experiments. ${ }^{\star} P<0.05,{ }^{* \star} P<0.001$

$\mathrm{Bcl}-\mathrm{XL}$ to regulate autophagy. ${ }^{25}$ Many $\mathrm{BH} 3-$ only proteins are mediators of autophagy, since they can disrupt the interaction between Beclin-1 and $\mathrm{Bcl}-2 / \mathrm{Bcl}-\mathrm{XL}$ to activate autophagy through the $\mathrm{BH} 3$ domains. ${ }^{47,52}$ BNIP3, a $\mathrm{BH} 3$ domaincontaining protein, can be upregulated by hypoxia-inducible factor-1 $a$ (HIF-1a) and displace Beclin-1 from Beclin-1/Bcl-2 or Beclin-1/Bcl-XL complexes, releasing Beclin-1 and regulating mitophagy ${ }^{26,52,53}$ We thus proposed that SPK2 might activate autophagy via its $\mathrm{BH} 3$ domain by a mechanism similar to BNIP3. We site directed mutated Leu-219 in the BH3 domain of SPK2 to Ala (SPK2-L219A) and established stable L219A transfected HT22 cells. ${ }^{23}$ The L219A mutation not only showed reduced level of SPK2 expression, but also revealed compromised autophagy activity, as the LC3II and the amount of autophagosomes was obviously less in L219A-HT22 cells than that in SPK2-HT22 cells. These results implicated that the autophagy activation by SPK2 is dependent on its $\mathrm{BH} 3$ domain.
To further verify the role of SPK2's BH3 domain in autophagy activation, we designed a cell permeable TatSPK2 peptide based on the sequence of the putative $\mathrm{BH} 3$ domain of SPK2. ${ }^{23,46}$ Our data confirmed that Tat-SPK2 peptide could enter HT22 cells. As expected, Tat-SPK2 peptide instead of Tat-L219A could upregulate LC3II and increase the autophagy flux. Importantly, Tat-SPK2 peptide protected HT22 cells as well as primary neurons against OGD injury, while inhibition of autophagy effectively abolished Tat-SPK2-mediated ischemic tolerance. All these results implied that the BH3 domain of SPK2 is sufficient to activate autophagy and exert neuroprotection against ischemia.

Although SPK2 inhibits proliferation and enhances apoptosis through its $\mathrm{BH} 3$ domain in different cell types, ${ }^{23}$ recent reports also show that SPK2 plays a role in regulating cancer cell proliferation and migration ${ }^{54,55}$ and SPK2 inhibitors may serve as the therapy for cancers. ${ }^{56}$ The discrepancy may be partly due to the expression level ${ }^{57}$ and cellular distribution of SPK2 in cells. The intracellular localization of SPK2 varies 

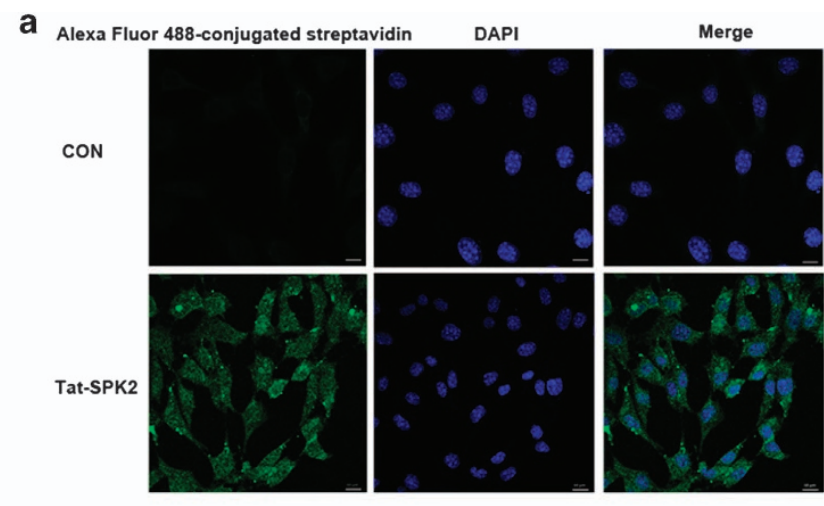

b
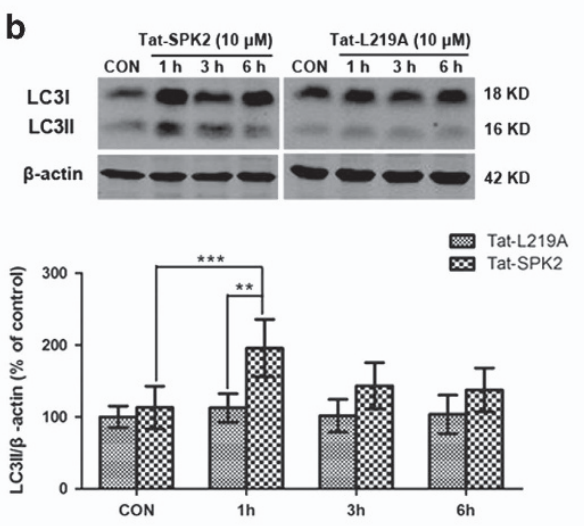

d

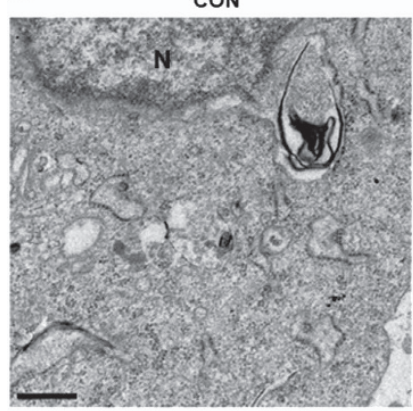

Tat-L219A (10 $\mu \mathrm{M} 1 \mathrm{~h})$

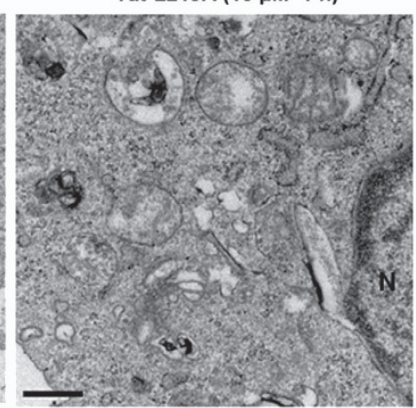

C $_{\text {Tat-SPK2 }(10 \mu \mathrm{M})}$
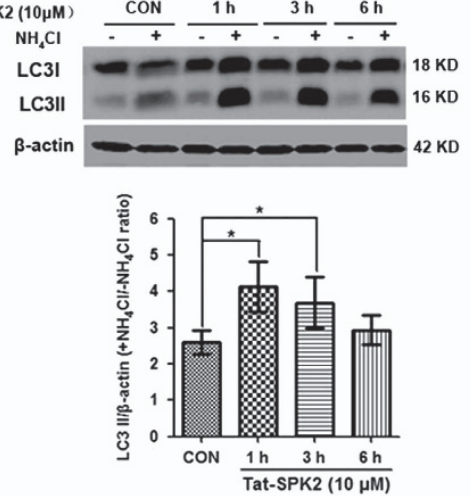

Tat-SPK2 $(10 \mu \mathrm{M} 1 \mathrm{~h})$

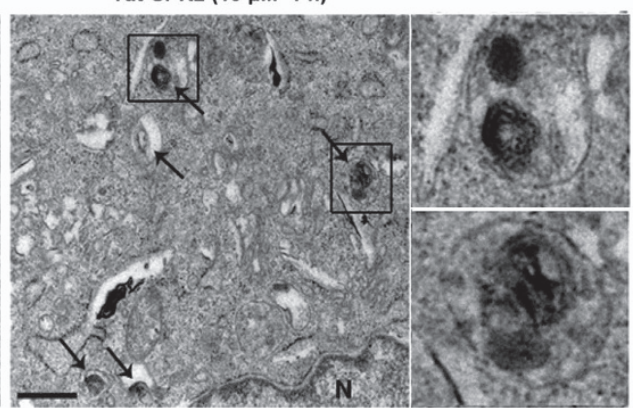

Figure 7 Tat-SPK2 peptide-induced autophagy in HT22 cells. (a) Intracellular staining pattern of biotin-conjugated Tat-SPK2 peptide. HT22 cells were treated with $10 \mu \mathrm{M}$ TatSPK2 or vehicle for $6 \mathrm{~h}$, and stained with Alexa Flour 488-conjugated streptavidin. Scale bar $=10 \mu \mathrm{m}$. (b) Tat-SPK2 but not Tat-L219A upregulated LC3II. HT22 cells were treated with $10 \mu \mathrm{M}$ Tat-SPK2 or Tat-L219A peptide for indicated time. Then the cells were harvested and subjected to western blot analysis. (c) Autophagic flux was examined by comparing LC3II/actin with or without $\mathrm{NH}_{4} \mathrm{Cl}$. HT22 cells were treated with $10 \mu \mathrm{M}$ Tat-SPK2 for indicated time, and then treated with $20 \mathrm{mM} \mathrm{NH} 4 \mathrm{Cl}$ for $24 \mathrm{~h}$. (d) Electron microscopic images show increased number of double-membrane vacuolar structure in HT22 cells treated with $10 \mu \mathrm{M}$ Tat-SPK2 peptide for $1 \mathrm{~h}$ but not in Tat-L219A peptidetreated HT22 cells. Scale bar $=0.5 \mu \mathrm{m}$. Arrows point to autophagosomes or autolysosomes. N: nucleus. Insets show the enlarged autophagosomes or autolysosomes taken from the boxed areas. Bar represents mean \pm S.D., $n=3$ independent experiments. ${ }^{*} P<0.05,{ }^{\star \star} P<0.01,{ }^{* \star *} P<0.001$

depending on cell types, activation state and/or density. ${ }^{58,59}$ Although SPK2 is often a nuclear kinase,${ }^{58-62}$ various groups also reported a cytoplasmic and mitochondrial localization of SPK2. ${ }^{58,60,63-65}$ In neurons, SPK2 can be expressed in the cytoplasm, mitochondria and nucleus under physiological or pathological conditions. ${ }^{41-44}$ Recent study suggest that overexpressed SPK2 in nucleus is neurotoxic and promotes DNA double-strand breaks in cultured primary neurons. ${ }^{44}$ However, our data showed that SPK2 was overexpressed in both the cytoplasm and nuclei of the SPK2 overexpressed neurons and HT22 cells. On the other hand, Bcl-2 was mainly expressed in the cytoplasm of both LV-SPK2-HT22 cells and SPK2- overexpressing neurons. Importantly, ISO and hypoxic preconditioning, a noxious stimulus that could be applied conveniently to elicit neuroprotection in vivo and in vitro, could upregulate endogenous SPK2 to activate autophagy. ${ }^{17}$ ISO seems to increase the colocalization of endogenous SPK2 and $\mathrm{Bcl}-2$ mainly in a cytoplasmic manner. From all these results, we assume that SPK2 might interact to $\mathrm{Bcl}-2$ in the cytoplasm to activate autophagy. It remains to be elucidated whether the different distribution of SPK2 contributes to different signaling regulating autophagy and cell survival.

Our results are supported by several studies showing that mild endogenous SPK2 activation is one of the protective 
HT22
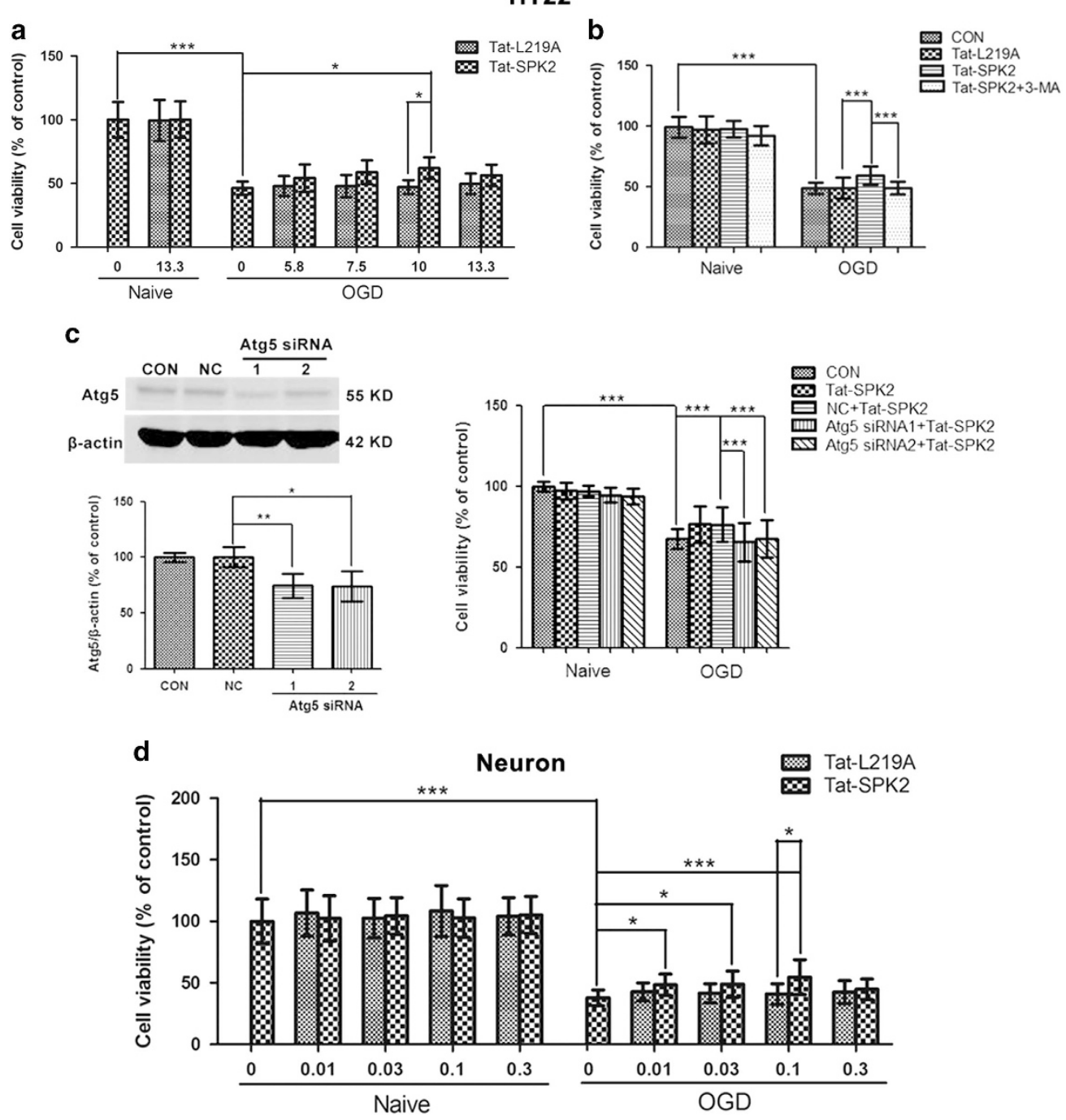

Figure 8 Tat-SPK2 peptide protected neural cells from OGD injury. (a) Tat-SPK2 peptide protected HT22 cells from OGD injury. HT22 cells were treated with Tat-SPK2 or Tat-L219A peptide at the indicated concentrations for $1 \mathrm{~h}$, and then were exposed to oxygen glucose deprivation (OGD) for $6 \mathrm{~h}$. The cell viability was examined by cell counting kit-8 assay. (b) 3-MA abolished Tat-SPK2-induced neuroprotection. Cells were treated with $10 \mu \mathrm{M}$ Tat-SPK2 or Tat-L219A peptide for $1 \mathrm{~h}$, and then were exposed to OGD for $6 \mathrm{~h}$. Cells were treated with $2.5 \mathrm{mM}$ 3-MA for $12 \mathrm{~h}$ during reperfusion. (c) Atg5 knockdown abolished Tat-SPK2-induced protection. HT22 cells were transfected with Atg5 siRNA using lipofectamine 2000. Atg5 was measured by western blotting. Seventy-two hours after transfection, cells were treated with $10 \mu \mathrm{M}$ Tat-SPK2 or Tat-L219A peptide for $1 \mathrm{~h}$, and then were exposed to OGD for $6 \mathrm{~h}$. (d) Tat-SPK2 peptide protected primary neurons from OGD injury. Primary neurons were treated with Tat-SPK2 or Tat-L219A peptide at the indicated concentrations for $3 \mathrm{~h}$, and then were exposed to OGD for $4 \mathrm{~h}$. Bar represents mean \pm S.D., $n=3 .{ }^{*} P<0.05,{ }^{* *} P<0.01,{ }^{* * *} P<0.001$. NC, negative control

mechanisms in both cerebral ischemia and myocardial ischemia. ${ }^{66,67}$ SPK2-mediated mechanism is involved in the protective effects of allicin against cerebral ischemia both in vivo and in vitro. ${ }^{68}$ SPK2 also contributes to the ischemic tolerance induced by cerebral or myocardial preconditioning. ${ }^{11,12,13,67,69}$ Overexpressed SPK2 in cardiomyocyte effectively inhibits apoptosis induced by hypoxia/ reoxygenation. ${ }^{69}$ In agreement with these reports, no significant apoptosis was observed in SPK2-transfected HT22 cells in this study. Instead, SPK2 overexpression and Tat-SPK2 peptide containing $\mathrm{BH} 3$ domain of SPK2 protected neurons from OGD injury. In fact, $\mathrm{BH} 3$ domain has dual functions in apoptosis and autophagy. ${ }^{4,52} \mathrm{BH}$ proteins like Beclin- ${ }^{25,70,71}$ and BNIP3 ${ }^{24}$ contributes to survival rather than apoptosis under certain conditions, such as nutrient deprivation and hypoxia. The $\mathrm{BH} 3$ domains of hypoxiainduced BNIP3/BNIP3L could induce autophagy and cell survival by disrupting the $\mathrm{Bcl}-2 /$ Beclin1complex without inducing cell death. ${ }^{24}$ We thus propose that SPK2, like lowaffinity $\mathrm{BH} 3$ binding partners BNIP3 and Beclin-1, will not trigger cell death during hypoxia, possibly because the interaction between SPK2 and Bcl-2 is too weak in comparison with those of BAD or BIM to trigger apoptosis. ${ }^{72}$ On the other hand, it was reported that high-level overexpression of SPK2 inhibits cell survival and proliferation, while low-level overexpression of SPK2 promotes cell survival and proliferation. $^{57}$ Thus the low level of SPK2 overexpression achieved in the present study (about twofold versus control) is similar to the effect of preconditioning to induce cell survival and protection. ${ }^{17}$ Furthermore, the dose of Tat-SPK2 peptide 


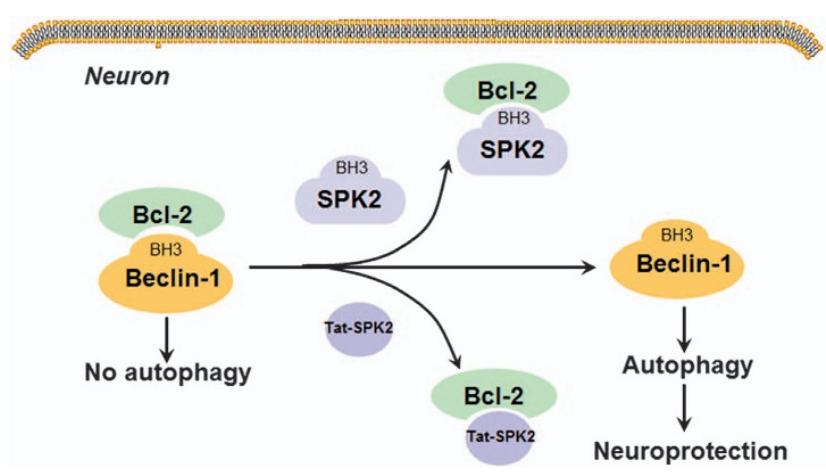

Figure 9 Proposed mechanism underlying autophagy activation induced by SPK2. Under normal conditions, Beclin-1 interacts with Bcl-2 via its BH3 domain to decrease the autophagy activity. Overexpression of SPK2 may displace Beclin-1 from Bcl-2 via its $\mathrm{BH} 3$ domain, leading to release of Beclin-1 and autophagy activation. Tat-SPK2 peptide containing $\mathrm{BH} 3$ domain of SPK2 might also bind to Bcl-2, and hence disrupt the interaction between $\mathrm{Bcl}-2$ and Beclin-1 to induce autophagy. Autophagy then contributes to the neuroprotection induced by SPK2 or Tat-SPK2 peptide

is also an important factor, as the lower dose of Tat-SPK2 might show stronger neuroprotection compared with higher dose. Tat-SPK2 peptide of 5.8-10 $\mu \mathrm{M}$ in HT22 cells and $0.01-$ $0.1 \mu \mathrm{M}$ in primary neurons showed a significant neuropotection against OGD injury. However, the higher dose of Tat-SPK2 (13.3 $\mu \mathrm{M}$ in HT22 cells and $0.3 \mu \mathrm{M}$ in neurons) does not show changes compared with the L219A peptide. Tat-SPK2 peptide even shows toxicity at the dose over $20 \mu \mathrm{M}$ in HT22 cells and over $5 \mu \mathrm{M}$ in primary neurons (data not shown). All these results further support the notion that expression level of SPK2 is important for its function.

In conclusion, our present results demonstrated that SPK2 could activate autophagy to protect neurons from OGD injury. SPK2, via its BH3 domain, could dissociate Beclin-1/Bcl-2 complex by interacting with Bcl-2 to activate autophagy. TatSPK2 peptide designed from the BH3 domain of SPK2 could activate autophagy and protect neurons against OGD injury. SPK2 and Tat-SPK2 peptide promote neuronal survival through induction of autophagy, implying that SPK2 inducers, Tat-SPK2 peptide or agents acting on Beclin-1/autophagy pathway may provide candidate therapeutic agents against ischemic stroke. Further studies are required to investigate whether Tat-SPK2 peptide is effective in animal models of ischemic stroke.

\section{Materials and Methods}

Cell culture. Primary cultured murine cortical neurons were prepared from the cortex of E15-17 mouse embryos. ${ }^{15,17}$ Briefly, timed pregnant mice (Center of Experimental Animals of Soochow University, certificate No 20020008, Grade II) were killed by decapitation under $2 \%$ isoflurane. Cortices from embryos were dissected into pre-cooled PBS, and then digested in $1.25 \%$ trypsin at $37^{\circ} \mathrm{C}$ for $15 \mathrm{~min}$. The trypsin digestion was stopped by DMEM (Gibco) with $10 \%$ fetal bovine serum (FBS; Gibco, Waltham, MA, USA) and the cell suspension was treated with DNase I (Sangon Biotech, Shanghai, China) for $3 \mathrm{~min}$. The cells were centrifuged at $500 \times g$ for $5 \mathrm{~min}$, and the supernatant was removed. The pellets were resuspended with neurobasal medium (NBM; Gibco) with 10\% B27 (Gibco) and $25 \mu \mathrm{M}$ glutamate (Sigma, St. Louis, MO, USA). After filtration through $40 \mu \mathrm{m}$ strainer, cells were plated on $0.1 \mathrm{mg} / \mathrm{ml}$ poly D-lysine (Sigma)-coated six-well $\left(6 \times 10^{5}\right.$ cell/well) or 24-well $\left(1.0 \times 10^{5} \mathrm{cell} /\right.$ well) dishes. The medium was changed to NBM with $10 \%$ B27 and $0.5 \mathrm{mM}$ glutamine (Sangon Biotech), $1 \%$ penicillin $\mathrm{G}$ and streptomycin after $24 \mathrm{~h}$. Half the medium was changed every 2 days. Cortical neurons were used for experiments after 7-10 days in vitro.

HT22 mouse hippocampal neuronal cells were obtained from Shanghai Institute of Cell Biology (Shanghai, China). Cells were cultured in Dulbecco's modified Eagle's medium (DMEM; Gibco) supplemented with 10\% FBS (Gibco), $100 \mathrm{U} / \mathrm{ml}$ streptomycin, $100 \mathrm{U} / \mathrm{ml}$ penicillin at $37^{\circ} \mathrm{C}$ in $5 \% \mathrm{CO}_{2} / 95 \%$ air.

Lentivirus-mediated SPK2 overexpression. LV-SPK2 mouse-EGFPHA-Puro $\left(5 \times 10^{8} \mathrm{TU} / \mathrm{ml}\right.$, GENEID 308589, NM020011) lentivirus was constructed by Shanghai Genechem Co. Ltd (Shanghai, China). On the second day in vitro (DIV2), cortical neurons were switched to NBM containing 10\% B27, $0.5 \mathrm{mM}$ glutamine and LV-SPK2 $(\mathrm{MOI}=10)$ or LV-vector (VEC) for $24 \mathrm{~h}$. Afterwards, the medium was changed to the regular medium. ${ }^{73}$ The GFP immunofluoresence was observed at 7 days after transfection with a fluorescence microscope (Olympus; IX71, Tokyo, Japan).

To establish stably infected HT22 cells, the HT22 cells were infected with LV-SPK2 mouse-EGFP-HA-Puro, LV-SPK2-L219A mouse-EGFP-HA-Puro lentivirus $\left(5 \times 10^{8} \mathrm{TU} / \mathrm{ml}\right.$, HA-NM020011-mu1; Genechem, Shanghai, China) or LV-vector $(\mathrm{MOI}=10)$ for $24 \mathrm{~h}$. Afterwards, the medium was changed to regular medium for $24 \mathrm{~h}$. Cells were then selected with $2 \mu \mathrm{g} / \mathrm{ml}$ puromycin (Sigma) for 2 weeks. ${ }^{74}$ The stable SPK2 or L219A infected HT22 cells were identified using GFP expression and western blot analysis.

Oxygen glucose deprivation. Primary cultured cortical neurons or HT22 cells were washed three times with Hepes balanced salt solution (HBSS: $\mathrm{NaCl}$ $140 \mathrm{mM}, \mathrm{KCl} 3.5 \mathrm{mM}, \mathrm{CaCl}_{2} 1.7 \mathrm{mM}, \mathrm{MgSO}_{4} 12 \mathrm{mM}, \mathrm{KH}_{2} \mathrm{PO}_{4} 0.4 \mathrm{mM}, \mathrm{NaHCO}_{3}$ $5 \mathrm{mM}$, Hepes $10 \mathrm{mM}$; pH 7.2-7.4). Cultures were placed in a chamber (BillupsRothenberg MC-101) filled with $95 \% \mathrm{~N}_{2}$ and $5 \% \mathrm{CO}_{2}$ at $37{ }^{\circ} \mathrm{C}$ for $4 \mathrm{~h}$ (cortical neurons) or $6 \mathrm{~h}$ (HT22 cells). Upon removal of the cultures from the chamber, the growth medium was changed back to normal medium. ${ }^{16}$

ISO model. Primary culture cortical neurons were exposed to $2 \%$ isoflurane (RWD Life Science, Shenzhen, China, R510-22, in 70\% nitrogen and $30 \%$ oxygen) at $37^{\circ} \mathrm{C}$ for $30 \mathrm{~min}$ in an airtight chamber. The neurons were handled 24 hours later. ${ }^{17}$

Cell viability assay. Cell Counting Kit-8 (CCK8; Dojindo Laboratories, Tokyo, Japan) or LDH (Beyotime, Shanghai, China) assay was used to determine cell viability. For CCK8 assay, $24 \mathrm{~h}$ after OGD, $10 \mu \mathrm{l}$ CCK8 was added into each well of 96-well plates, which were incubated at $37^{\circ} \mathrm{C}$ for $2 \mathrm{~h}$. Optical density was measured at $450 \mathrm{~nm}$ using a plate reader (ELX 800; Bio-Tek, Winooski, VT, USA). For LDH assay, the neurons and culture medium were lysed in PBS containing 1\% Triton $\mathrm{X}-100$ at $37^{\circ} \mathrm{C}$ for $30 \mathrm{~min}$, respectively. The LDH activities in both the cell lysates and the culture mediums were assayed with the assay kit following the manufacturer's instructions. LDH leakage was calculated as follows: LDH leakage $(\%)=\mathrm{LDH}$ culture medium/(LDH culture medium+LDH cell lysates) $\times 100 \%{ }^{73}$

Sphingosine kinase 2 activity assay. SPK2 activity was determined using the fluorescent substrate NBD-sphingosine (avanti Polar Lipids; 810205P). ${ }^{12,75} \mathrm{HT} 22$ cells were collected in lysis buffer (Hepes $50 \mathrm{mM}, \mathrm{pH} \mathrm{7.4,} \mathrm{KCl} 10 \mathrm{mM}$, glycerol 20\%, dithiothreitol $2 \mathrm{mM}, \mathrm{NaF} 15 \mathrm{mM}$, semicarbazide $2 \mathrm{mM}$, EDTA-free complete protease inhibitor (Roche, Basel, Switzerland)). Twenty-five micrograms of lysate protein reacted with reaction mixture (Hepes $50 \mathrm{mM}, \mathrm{pH} 7.4, \mathrm{MgCl}_{2} 15 \mathrm{mM}$, glycerol $10 \%$, ATP $10 \mathrm{mM}, \mathrm{NaF} 15 \mathrm{mM}$, semicarbazide $2 \mathrm{mM}$, NBD-sphingosine $10 \mu \mathrm{M}$ and $\mathrm{KCl}$ $1 \mathrm{M}$ (for SPK2 specificity $\left.{ }^{12}\right)$ ). After $1 \mathrm{~h}$, the reaction was stopped by $50 \mu \mathrm{l} 1 \mathrm{M} \mathrm{K}_{3} \mathrm{PO}_{4}$ (pH 8.5). Then $250 \mu \mathrm{l} \quad \mathrm{CHCl}_{3} / \mathrm{CH}_{3} \mathrm{OH}$ (2:1) was added and the lysates were centrifuged at $15000 \times g$ for $1 \mathrm{~min}$. One hundred microliters upper aqueous phase was incubated with $50 \mu \mathrm{l}$ dimethylformamide and NBD fluorescence was read by Multiskan Spectrum Microplate Reader (TECAN Infinite M1000 Pro, Mannedorf, Siwtzerland), excitation at $485 \mathrm{~nm}$, emission at $538 \mathrm{~nm}$ ).

Western blot analysis. Cells were rinsed twice with cooled PBS and lysed in a buffer containing Tris- $\mathrm{HCl}(\mathrm{pH} 7.4) 10 \mathrm{mM}, \mathrm{NaCl} 150 \mathrm{mM}, 1 \%$ Triton X-100, 1\% sodium dexoxycholate, $0.1 \%$ SDS, EDTA $5 \mathrm{mM}$ and EDTA-free complete protease inhibitor (Roche). Protein concentrations were determined by BCA assay. Equal amounts $(10-30 \mu \mathrm{g})$ of total protein extracts were separated by SDS-PAGE and transferred to nitrocellulose membranes. Western blot analysis was used to measure the levels of SPK2 (1:200; Abgent, San Diego, CA, USA, AP7238a), HA-Tag (1:1000; CST3724S), SPK1 (1:1000, Abgent AP7237c), LC3 (1: 1000; Abcam, Cambridge, UK, ab62721), Beclin-1 (1 : 1000, Santa Cruz, Dallas, TX, USA, sc-11427). Expression levels were normalized to $\beta$-actin (1: 10000; Sigma A5441). 
Hoechst staining. Cells were fixed with $4 \%$ paraformaldehyde for $15 \mathrm{~min}$ and the nuclei were stained with Hoechst 33342 for $15 \mathrm{~min}$. Fluorescence was observed with a fluorescence microscope (Olympus, IX71). Cells undergoing apoptosis were characterized by brightly stained, condensed nuclei. The percentages of apoptotic cells were counted in four random fields.

SPK2 and/or bcl-2 immunofluorescence. Cells were fixed with $4 \%$ paraformaldehyde for $15 \mathrm{~min}$ and incubated with PBS containing $0.1 \%$ Triton X-100 for $30 \mathrm{~min}$. After blocking with $1 \% \mathrm{BSA}$ for $1 \mathrm{~h}$, cells were incubated with antibodies against SPK2 (1:100) and/or Bcl-2(1:20; Santa Cruz sc-7382) at $4{ }^{\circ} \mathrm{C}$ for $24 \mathrm{~h}$, and with anti-rabbit $\lg \mathrm{G}(\mathrm{H}+\mathrm{L})$ secondary antibody, Dylight 633 (1:500; Invitrogen) and/or anti-mouse IgG $(\mathrm{H}+\mathrm{L})$ secondary antibody, DyLight 488 (1:500; Invitrogen) for $2 \mathrm{~h}$. Then the cells were stained with DAPI (1:10000; sigma D9564) for 10 min. Images of fluorescence were acquired using a laser scanning confocal microscopy (ZEISS LSM710, Oberkochen, Germany). ${ }^{17}$

Nuclear extraction. Cells were centrifuged at $1500 \times g$ for 5 min at $4{ }^{\circ} \mathrm{C}$ and lysed in buffer A (sucrose $1 \mathrm{M}, \mathrm{CaCl}_{2} 0.1 \mathrm{M}, \mathrm{MgAc} 1 \mathrm{M}$, EDTA, DTT $100 \mathrm{nM}, \mathrm{NP} 40$ $0.5 \%$, EDTA-free complete protease inhibitor (Roche)). The lysates were then centrifuged at $600 \times g$ for $15 \mathrm{~min}$ to separate the cytoplasmic fraction of the cell extract. The pellets were resuspended in buffer $\mathrm{B}$ (sucrose $1 \mathrm{M}, \mathrm{CaCl}_{2} 0.1 \mathrm{M}, \mathrm{MgAc}$ $1 \mathrm{M}$, EDTA $250 \mathrm{mM}$, DTT $100 \mathrm{nM}$ ), and centrifuged at $600 \times \mathrm{g}$ for $10 \mathrm{~min}$. The pellets were taken as the nuclear fraction. ${ }^{76}$ Lamin B (Santa Cruz sc6216) and GAPDH (Abcam, ab8245) were used as nuclear and cytoplasmic markers.

Co-immunoprecipitation. Cells were harvested and lysed in a buffer containing Tris- $\mathrm{HCl} 50 \mathrm{mM}$ (pH 7.4), $\mathrm{NaCl} 150 \mathrm{mM}, 0.05 \%$ sodium deoxycholate, $1 \%$ NP40 and EDTA-free complete protease inhibitor (Roche). The lysates were precleaned with protein G-agarose (Roche) for $1 \mathrm{~h}$, incubated with antibody (Bcl-2, Santa Cruz sc-7382; HA-Tag, CST3724S) or IgG (normal mouse IgG, Santa Cruz sc-2025, normal rabbit IgG, Santa Cruz sc-2027) overnight. After washing away unbound antibody, lysates were incubated with protein G-agarose for 4-8 h. ${ }^{17}$ The immunoprecipitates were analyzed by western blotting using antibody against $\mathrm{HA}$, Bcl-2 (Santa Cruz sc-492) or Beclin-1.

GST pull-down. Glutathione-agarose (Santa Cruz sc-2009) beads were washed with $1 \%$ Triton X-100 PBS, and were incubated with GST (Flarebio, Wuhan, China, CSB-RP101744Ba) or Bcl-2 GST fusion protein (PTG, Wuhan, China, ag3508) for $1 \mathrm{~h}$ at $4{ }^{\circ} \mathrm{C}$ under constant mixing. After washing away unbound proteins three times with pre-cooled lysis buffer, the GST-bead complex was incubated overnight with cell lysates. ${ }^{77}$ The bound proteins eluted from the beads were subjected to western blot analysis using anti-HA or anti GST antibody $\left(1: 1000\right.$, Santa Cruz sc-138). ${ }^{78}$

Electron microscopy. HT22 Cells were harvested and fixed in $2.5 \%$ gluteraldehyde in $0.1 \mathrm{M}$ phosphate buffer $(\mathrm{pH} 7.4)$ at $4{ }^{\circ} \mathrm{C}$. The cell pellets were post-fixed with $1 \%$ Osmium tetroxide, dehydrated through acetone and then immersed in resin. After hardening, the blocks were sectioned at $50 \mathrm{~nm}$ thickness and stained with lead citrate. Then the autophagosomes or antolysosomes were viewed on a Transmission Electron Microscope (JEOL JEM 1230,Tokyo, Japan). Autophagosomes were defined as double- or multiple-membrane structures surrounding cytoplasmic constituents, while autolysosomes were defined as single membrane structures containing cytoplasmic components. ${ }^{79}$ At least 10 fields of view of each sample were captured. Three independent experiments with different samples were analyzed.

Peptide synthesis and treatment. Tat-SPK2 peptide and Tat-L219A peptide (Figure 6a) were synthesized by Chinese Peptide Company (Hangzhou, China, purity 95\%). Tat-SPK2 peptide sequence consisted of 11 amino acids from the Tat protein transduction domain (PTD), ${ }^{46}$ a GG linker, and the 18 amino acids derived from the SPK2 $210-227$. $^{23}$ The control peptide, Tat-L219A, consisted of PTD, a GG linker and 18 amino acids of SPK2 210-227 containing one substitution, L219A. The Tat-SPK2 and Tat-L219A peptides were dissolved in double distilled water and then diluted to the working solution with complete medium. To determine the autophagy activity, HT22 cells were pretreated with the peptides at $10 \mu \mathrm{M}$ for 1-6 h. For cell viability analysis, HT22 cells were pretreated with the peptides at the indicated concentrations for $1 \mathrm{~h}$ before $\mathrm{OGD}$ and during the whole OGD period. Primary neurons were pretreated with the peptides for $3 \mathrm{~h}$, and then exposed to OGD for $4 \mathrm{~h}$. The peptide was removed during OGD episode.
Peptide entry assay. HT22 cells were treated with $10 \mu \mathrm{M}$ biotinylated Tat-SPK2 for $6 \mathrm{~h}$. Cells were fixed with $4 \%$ paraformaldehyde for $10 \mathrm{~min}$ at room temperature. Then HT22 cells were permeabilized with $0.1 \%$ Triton X-100 and stained with Alexa Fluor 488-conjugated streptavidin for $1 \mathrm{~h} .{ }^{47}$ Fluorescence was observed by a laser scanning confocal microscope (ZEISS LSM710).

Drug treatment. Cortical neurons or HT22 cells were treated with autophagy inhibitor (Sigma; M9281) for 12-24 h following OGD. ${ }^{16,34,36}$ Neurons or HT22 cells were treated with an lysosomal inhibitor $\mathrm{NH}_{4} \mathrm{Cl}$ (Greagent G17391B) $20 \mathrm{mM}$ for 24 $h^{32,33,74}$

SiRNA. Small-interfering RNAs against Beclin-1 (siRNA1, sense: 5'-GGAGU GGAAUGAAAUCAAUTT-3', antisense: 5'-AUUGA -UUUCAUUCCACUCCTT-3'; siRNA 2, sense: 5'-GAUCCUGG -ACCGGGUCACCTT-3', antisense: 5'-GGUGAC CCGGUCCAGGAUCTT-3') ${ }^{17}$ or Atg5 (siRNA1, sense: 5'-GCGGUUGAGGCUC ACUUUATT-3', antisense: 5'-UAAAGUGAGCCUCAACCGCTT-3; siRNA 2, sense: 5'-CCAUCAACCGGAAACUCAUTT-3', antisense: 5'-AUGAGUUUCCGGUUGAU GGTT-3') were synthesized by Genepharma (Shanghai, China). Transfection of Beclin-1 siRNA (40 nM) in cortical neurons was performed using lipofectamine 2000 (Invitrogen) on day 6 in vitro (DIV6) $)^{80}$ according to the manufacturer's instructions. HT22 cells were transfected with Atg5 siRNA (80nm) using lipofectamine 2000. The cells were also transfected with a control scrambled RNA targeting a sequence not sharing homology with the Mus Musculus Genome (negative control, NC). The suppression of Beclin-1 or Atg5 expression was confirmed with western blotting.

Statistical analysis. The data were expressed as mean \pm S.D. The significance between groups was determined with one-way ANOVA, followed by the Newman-Keuls test for post hoc analysis.

\section{Conflict of Interest}

The authors declare no conflict of interest.

Acknowledgements. This work was supported by grants from the National Natural Science Foundation of China (No. 81173057, 81373402 and 81673421). CW is supported by a Marie Curie Career Integration Grant (631246).

1. Sun N, Keep RF, Hua Y, Xi G. Critical role of the sphingolipid pathway in stroke: a review of current utility and potential therapeutic targets. Trans/ Stroke Res 2016; 7: 420-438.

2. Bernacchioni C, Cencetti F, Blescia S. Sphingosine kinase/sphingosine 1-phosphate axis: a new player for insulin-like growth factor-1-induced myoblast differentiation. Skelet Muscle 2012; 2: 15.

3. Gestaut MM, Antoon JW, Burow ME, Beckman BS. Inhibition of sphingosine kinase-2 ablates androgen resistant prostate cancer proliferation and survival. Pharmacol Rep 2014; 66: $174-178$.

4. Wang Q, Li J, Li G, Li Y, Xu C, Li M et al. Prognostic significance of sphingosine kinase 2 expression in non-small cell lung cancer. Tumour Biol 2014; 35: 363-368.

5. Zhang L, Urtz N, Gaertner F, Legate KR, Petzold T, Lorenz M et al. Sphingosine kinase 2 (Sphk2) regulates platelet biogenesis by providing intracellular sphingosine 1-phosphate (S1P). Blood 2013; 122: 791-802.

6. Urtz N, Gaertner F, von Bruehl ML, Chandraratne S, Rahimi F, Zhang L et al. Sphingosine 1-Phosphate Produced by Sphingosine Kinase 2 Intrinsically Controls Platelet Aggregation In Vitro and In Vivo. Circ Res 2015; 117: 376-387.

7. Liu $Q$, Rehman H, Shi Y, Krishnasamy Y, Lemasters JJ, Smith $C D$ et al. Inhibition of sphingosine kinase-2 suppresses inflammation and attenuates graft injury after liver transplantation in rats. PLOS ONE 2012; 7: e41834.

8. Baker DA, Eudaly J, Smith CD, Obeid LM, Gilkeson GS. Impact of sphingosine kinase 2 deficiency on the development of TNF-alpha-induced inflammatory arthritis. Rheumatol Int 2013; 33: 2677-2681

9. Xu T, Li L, Huang C, Peng Y, Li J. Sphingosine kinase 2: a controversial role in arthritis. Rheumatol Int 2014; 34: 1015-1016.

10. Snider AJ, Ruiz P, Obeid LM, Oates JC. Inhibition of Sphingosine Kinase-2 in a murine model of lupus nephritis. PLOS ONE 2013; 8: 1-9.

11. Yung $L M$, Wei $Y$, Qin T, Wang $Y$, Smith $C D$, Waeber $C$. Sphingosine kinase 2 mediates cerebral preconditioning and protects the mouse brain against ischemic injury. Stroke 2012; 43: 199-204.

12. Wacker BK, Park TS, Gidday JM. Hypoxic preconditioning-induced cerebral ischemic tolerance: role of microvascular sphingosine kinase 2. Stroke 2009; 40: 3342-3348.

13. Wacker BK, Freie AB, Perfater JL, Gidday JM. Junctional protein regulation by sphingosine kinase 2 contributes to blood-brain barrier protection in hypoxic preconditioning-induced cerebral ischemic tolerance. J Cereb Blood Flow Metab 2012; 32: 1014-1023. 
14. Maday S, Holzbaur EL. Compartment-specific regulation of autophagy in primary neurons. $J$ Neurosci 2016; 36: 5933-5945.

15. Sheng R, Zhang LS, Han R, Liu XQ, Gao B, Qin ZH. Autophagy activation is associated with neuroprotection in a rat model of focal cerebral ischemic preconditioning. Autophagy 2010; 6 : 482-494.

16. Sheng R, Liu X-Q, Zhang L-S, Gao B, Han R, Wu $Y-Q$ et al. Autophagy regulates endoplasmic reticulum stress in ischemic preconditioning. Autophagy 2012; 8: 310-325.

17. Sheng R, Zhang TT, Felice VD, Qin T, Qin ZH, Smith CD et al. Preconditioning stimuli induce autophagy via Sphingosine Kinase 2 in mouse cortical neurons. J Biol Chem 2014; 289: 20845-20857

18. Pattingre SBC, Levade T, Levine B, Codogno P. Ceramide-induced autophagy: to junk or to protect cells? Autophagy 2009; 5: 558-560

19. Lavieu G, Scarlatti F, Sala G, Carpentier S, Levade T, Ghidoni R et al. Regulation of autophagy by sphingosine kinase 1 and its role in cell survival during nutrient starvation. J Biol Chem 2006; 281: 8518-8527.

20. Moruno Manchon JF, Uzor NE, Finkbeiner S, Tsvetkov AS. SPHK1/sphingosine kinase 1-mediated autophagy differs between neurons and SH-SY5Y neuroblastoma cells. Autophagy 2016; 12: 1418-1424.

21. Moruno Manchon JF, Uzor NE, Dabaghian Y, Furr-Stimming EE, Finkbeiner S, Tsvetkov AS Cytoplasmic sphingosine-1-phosphate pathway modulates neuronal autophagy. Sci Rep 2015; 5: 15213 .

22. Rolando M, Escoll P, Nora T, Botti J, Boitez V, Bedia C et al. Legionella pneumophila S1P-lyase targets host sphingolipid metabolism and restrains autophagy. Proc Natl Acad Sci USA 2016; 113: 1901-1906.

23. Liu H, Toman RE, Goparaju SK, Maceyka M, Nava VE, Sankala H et al. Sphingosine kinase type 2 is a putative BH3-only protein that induces apoptosis. J Biol Chem 2003; 278: 40330-40336.

24. Bellot G, Garcia-Medina R, Gounon P, Chiche J, Roux D, Pouyssegur J et al. Hypoxiainduced autophagy is mediated through hypoxia-inducible factor induction of BNIP3 and BNIP3L via their BH3 domains. Mol Cell Biol 2009; 29: 2570-2581.

25. Maiuri MC, Le Toumelin G, Criollo A, Rain JC, Gautier F, Juin P et al. Functional and physical interaction between $\mathrm{Bcl}-\mathrm{X}(\mathrm{L})$ and a BH3-like domain in Beclin-1. EMBO J 2007; 26: 2527-2539.

26. Zhang H, Bosch-Marce M, Shimoda LA, Tan YS, Baek JH, Wesley JB et al. Mitochondrial autophagy is an HIF-1-dependent adaptive metabolic response to hypoxia. $J$ Biol Chem 2008; 283: 10892-10903.

27. Zhang X, Yan H, Yuan Y, Gao J, Shen Z, Cheng Y et al. Cerebral ischemia-reperfusioninduced autophagy protects against neuronal injury by mitochondrial clearance. Autophagy 2013; 9: 1321-1333.

28. Zhang X, Yuan Y, Jiang L, Zhang J, Gao J, Shen Z et al. Endoplasmic reticulum stress induced by tunicamycin and thapsigargin protects against transient ischemic brain injury: Involvement of PARK2-dependent mitophagy. Autophagy 2014; 10: 1801-1813.

29. Shen Z, Zheng Y, Wu J, Chen Y, Wu X, Zhou Y et al. PARK2-dependent mitophagy induced by acidic postconditioning protects against focal cerebral ischemia and extends the reperfusion window. Autophagy 2017; 13: 473-485.

30. Palubinsky AM, Stankowski JN, Kale AC, Codreanu SG, Singer RJ, Liebler DC et al. CHIP is an essential determinant of neuronal mitochondrial stress signaling. Antioxid Redox Signal 2015; 23: 535-549.

31. Lu Q, Harris VA, Kumar S, Mansour HM, Black SM. Autophagy in neonatal hypoxia ischemic brain is associated with oxidative stress. Redox Biol 2015; 6: 516-523.

32. Cortes CJ, Miranda HC, Frankowski H, Batlevi Y, Young JE, Le A et al. Polyglutamineexpanded androgen receptor interferes with TFEB to elicit autophagy defects in SBMA. Nat Neurosci 2014; 17: 1180-1189.

33. Lee YR, Wang PS, Wang JR, Liu HS. Enterovirus 71-induced autophagy increases viral replication and pathogenesis in a suckling mouse model. J Biomed Sci 2014; 21: 80.

34. Seglen PO, Gordon PB. 3-Methyladenine: specific inhibitor of autophagic/lysosomal protein degradation in isolated rat hepatocytes. Proc Natl Acad Sci USA 1982; 79: 1889-1892.

35. Farkas $T$, Daugaard $M$, Jaattela $M$. Identification of small molecule inhibitors of phosphatidylinositol 3-kinase and autophagy. J Biol Chem 2011; 286: 38904-38912.

36. Kim H, Choi J, Ryu J, Park SG, Cho S, Park BC et al. Activation of autophagy during glutamate-induced HT22 cell death. Biochem Biophys Res Commun 2009; 388: 339-344.

37. Itakura E, Kishi C, Inoue K, Mizushima N. Beclin 1 forms two distinct phosphatidylinositol 3kinase complexes with mammalian Atg14 and UVRAG. Mol Biol Cell 2008; 19: 5360-5372.

38. Pattingre S, Tassa A, Qu X, Garuti R, Liang XH, Mizushima N et al. Bcl-2 antiapoptotic proteins inhibit Beclin 1-dependent autophagy. Cell 2005; 122: 927-939.

39. De Amicis F, Guido C, Santoro M, Giordano F, Donà A, Rizza $P$ et al. Ligand activated progesterone receptor $B$ drives autophagy-senescence transition through a Beclin-1/Bcl-2 dependent mechanism in human breast cancer cells. Oncotarget 2016; 7: 57955-57969.

40. Dai JP, Zhao XF, Zeng J, Wan QY, Yang JC, Li WZ et al. Drug screening for autophagy inhibitors based on the dissociation of Beclin1-Bcl2 complex using BiFC technique and mechanism of eugenol on anti-influenza A virus activity. PLOS ONE 2013; 8: e61026.

41. Chakraborty G, Saito M, Shah R, Mao RF, Vadasz C. Ethanol triggers sphingosine 1-phosphate elevation along with neuroapoptosis in the developing mouse brain. J Neurochem 2012; 121: 806-817.

42. Hasegawa Y, Suzuki H, Altay O, Rolland W, Zhang JH. Role of the sphingosine metabolism pathway on neurons against experimental cerebral ischemia in rats. Trans/ Stroke Res 2013; 4: $524-532$.
43. Sivasubramanian M, Kanagaraj N, Dheen ST, Tay SS. Sphingosine kinase 2 and sphingosine-1-phosphate promotes mitochondrial function in dopaminergic neurons of mouse model of Parkinson's disease and in MPP+ -treated MN9D cells in vitro. Neuroscience 2015; 290: 636-648.

44. Moruno-Manchon JF, Uzor NE, Blasco MP, Mannuru S, Putluri N, Furr-Stimming EE et al. Inhibiting sphingosine kinase 2 mitigates mutant huntingtin-induced neurodegeneration in neuron models of Huntington disease. Hum Mol Genet 2017; 26: 1305-1317.

45. Liu K, Shi Y, Guo X, Wang S, Ouyang Y, Hao M et al. CHOP mediates ASPP2-induced autophagic apoptosis in hepatoma cells by releasing Beclin-1 from Bcl-2 and inducing nuclear translocation of Bcl-2. Cell Death Dis 2014; 5: e1323.

46. Shoji-Kawata S, Sumpter R, Leveno M, Campbell GR, Zou Z, Kinch L et al. Identification of a candidate therapeutic autophagy-inducing peptide. Nature 2013; 494: 201-206.

47. Liu Y, Shoji-Kawata S, Sumpter RM Jr, Wei Y, Ginet V, Zhang L et al. Autosis is a Na+,K +-ATPase-regulated form of cell death triggered by autophagy-inducing peptides, starvation, and hypoxia-ischemia. Proc Natl Acad Sci USA 2013; 110: 20364-20371.

48. Lin J, Huang Z, Wu H, Zhou W, Jin P, Wei P et al. Inhibition of autophagy enhances the anticancer activity of silver nanoparticles. Autophagy 2014; 10: 2006-2020.

49. Jiang LB, Cao L, Yin XF, Yasen M, Yishake M, Dong J et al. Activation of autophagy via Ca(2 +)-dependent AMPK/mTOR pathway in rat notochordal cells is a cellular adaptation under hyperosmotic stress. Cell Cycle 2015; 14: 867-879.

50. Klionsky DJ, Abdalla FC, Abeliovich H, Abraham RT, Acevedo-Arozena A, Adeli K et al. Guidelines for the use and interpretation of assays for monitoring autophagy. Autophagy 2016; 12: 1-222.

51. Chittenden T. BH3 domains: intracellular death-ligands critical for initiating apoptosis. Cancer Cell 2002; 2: 165-166.

52. Maiuri MC, Criollo A, Tasdemir E, Vicencio JM, Tajeddine N, Hickman JA et al. BH3-only proteins and $\mathrm{BH} 3$ mimetics induce autophagy by competitively disrupting the interaction between Beclin 1 and Bcl-2/Bcl-X(L). Autophagy 2007; 3: 374-376.

53. Mazure NM, Pouysségur J. Atypical BH3-domains of BNIP3 and BNIP3L lead to autophagy in hypoxia. Autophagy 2009; 5: 868-869.

54. Venkata JK, An N, Stuart R, Costa LJ, Cai H, Coker W et al. Inhibition of sphingosine kinase 2 downregulates the expression of $\mathrm{C}-\mathrm{Myc}$ and $\mathrm{Mcl}-1$ and induces apoptosis in multiple myeloma. Blood 2014; 124: 1915-1925.

55. Gao $\mathrm{P}$, Smith $\mathrm{CD}$. Ablation of sphingosine kinase-2 inhibits tumor cell proliferation and migration. Mol Cancer Res 2011; 9: 1509-1519.

56. Neubauer HA, Pitson SM. Roles, regulation and inhibitors of sphingosine kinase 2 . FEBS J 2013; 280: 5317-5336

57. Neubauer HA, Pham DH, Zebol JR, Moretti PA, Peterson AL, Leclercq TM et al. An oncogenic role for sphingosine kinase 2. Oncotarget 2016; 7: 64886-64899.

58. Igarashi N, Okada T, Hayashi S, Fujita T, Jahangeer S, Nakamura S. Sphingosine kinase 2 is a nuclear protein and inhibits DNA synthesis. J Biol Chem 2003; 278 46832-46839.

59. Okada T, Ding G, Sonoda H, Kajimoto T, Haga Y, Khosrowbeygi A et al. Involvement of $\mathrm{N}$-terminal-extended form of sphingosine kinase 2 in serum-dependent regulation of cell proliferation and apoptosis. J Biol Chem 2005; 280: 36318-36325

60. Ding G, Sonoda H, Yu H, Kajimoto T, Goparaju SK, Jahangeer S et al. Protein kinase D-mediated phosphorylation and nuclear export of sphingosine kinase 2. J Biol Chem 2007; 282: 27493-27502

61. Hait NC, Allegood J, Maceyka M, Strub GM, Harikumar KB, Singh SK et al. Regulation of histone acetylation in the nucleus by sphingosine-1-phosphate. Science 2009; 325 : 1254-1257.

62. Hait NC, Wise LE, Allegood JC, O'Brien M, Avni D, Reeves TM et al. Active, phosphorylated fingolimod inhibits histone deacetylases and facilitates fear extinction memory. Nat Neurosci 2014; 17: 971-980

63. Venkataraman K, Thangada S, Michaud J, Oo ML, Ai Y, Lee YM et al. Extracellular export of sphingosine kinase-1a contributes to the vascular S1P gradient. Biochem J 2006; 397 461-471.

64. Hait NC, Sarkar S, Le Stunff H, Mikami A, Maceyka M, Milstien S et al. Role of sphingosine kinase 2 in cell migration toward epidermal growth factor. J Biol Chem 2005; 280 29462-29469.

65. Strub GM, Paillard M, Liang J, Gomez L, Allegood JC, Hait NC et al. Sphingosine-1phosphate produced by sphingosine kinase 2 in mitochondria interacts with prohibitin 2 to regulate complex IV assembly and respiration. FASEB J 2011; 25: 600-612.

66. Pfeilschifter W, Czech-Zechmeister B, Sujak M, Mirceska A, Koch A, Rami A et al. Activation of sphingosine kinase 2 is an endogenous protective mechanism in cerebral ischemia. Biochem Biophys Res Commun 2011; 413: 212-217.

67. Vessey DA, Li L, Jin ZQ, Kelley M, Honbo N, Zhang J et al. A sphingosine kinase form 2 knockout sensitizes mouse myocardium to ischemia/reoxygenation injury and diminishes responsiveness to ischemic preconditioning. Oxid Med Cell Longev 2011; 2011: 961059.

68. Lin JJ, Chang T, Cai WK, Zhang Z, Yang YX, Sun C et al. Post-injury administration of allicin attenuates ischemic brain injury through sphingosine kinase 2 : in vivo and in vitro studies. Neurochem Int 2015; 89: 92-100.

69. Zhang R, Li L, Yuan L, Zhao M. Hypoxic preconditioning protects cardiomyocytes against hypoxia/reoxygenation-induced cell apoptosis via sphingosine kinase 2 and FAK/AKT pathway. Exp Mol Pathol 2016; 100: 51-58.

70. Sinha S, Levine B. The autophagy effector Beclin 1: a novel BH3-only protein. Oncogene 2008; 27(Suppl 1): S137-S148. 
71. Maejima Y, Isobe M, Sadoshima J. Regulation of autophagy by Beclin 1 in the heart. J Mol Cell Cardiol 2016; 95: 19-25.

72. Mazure NM, Pouyssegur J. Atypical BH3-domains of BNIP3 and BNIP3L lead to autophagy in hypoxia. Autophagy 2009; 5: 868-869.

73. Zhou JH, Zhang TT, Song DD, Xia YF, Qin ZH, Sheng R. TIGAR contributes to ischemic tolerance induced by cerebral preconditioning through scavenging of reactive oxygen species and inhibition of apoptosis. Sci Rep 2016; 6: 27096.

74. Zhang XY, Zhang TT, Song DD, Zhou J, Han R, Qin ZH et al. Endoplasmic reticulum chaperone GRP78 is involved in autophagy activation induced by ischemic preconditioning in neural cells. Mol Brain 2015; 8: 20.

75. Don AS, Martinez-Lamenca C, Webb WR, Proia RL, Roberts E, Rosen H. Essential requirement for sphingosine kinase 2 in a sphingolipid apoptosis pathway activated by FTY720 analogues. J Biol Chem 2007; 282: 15833-15842.

76. Argüelles S, Camandola S, Hutchison ER, Cutler RG, Ayala A, Mattson MP. Molecular control of the amount, subcellular location and activity state of translation Elongation Factor 2 (eEF-2) in neurons experiencing stress. Free Radic Biol Med 2013; 61 : $61-71$.

77. Ren H, Fu K, Mu C, Zhen X, Wang G. L166P mutant DJ-1 promotes cell death by dissociating Bax from mitochondrial Bcl-XL. Mol Neurodegener 2012; 7: 40.

78. Guan JJ, Zhang XD, Sun W, Qi L, Wu JC, Qin ZH. DRAM1 regulates apoptosis through increasing protein levels and lysosomal localization of BAX. Cell Death Dis 2015; 6: e1624.
79. Mizushima N, Yamamoto A, Hatano M, Kobayashi Y, Kabeya Y, Suzuki K et al. Dissection of autophagosome formation using Apg5-deficient mouse embryonic stem cells. J Cell Biol 2001; 152: 657-668.

80. Tonges L, Lingor P, Egle R, Dietz GP, Fahr A, Bahr M. Stearylated octaarginine and artificial virus-like particles for transfection of siRNA into primary rat neurons. RNA 2006; 12 : 1431-1438.

(c) (i) Cell Death and Disease is an open-access journal published by Nature Publishing Group. This work is licensed under a Creative Commons Attribution 4.0 International License. The images or other third party material in this article are included in the article's Creative Commons license, unless indicated otherwise in the credit line; if the material is not included under the Creative Commons license, users will need to obtain permission from the license holder to reproduce the material. To view a copy of this license, visit http://creativecommons.org/licenses/by/4.0/

(C) The Author(s) 2017

Supplementary Information accompanies this paper on Cell Death and Disease website (http://www.nature.com/cddis) 